\title{
An Emergent Model of Orientation Selectivity in Cat Visual Cortical Simple Cells
}

\author{
David C. Somers, ${ }^{1}$ Sacha B. Nelson, ${ }^{2}$ and Mriganka Sur ${ }^{1}$ \\ 'Department of Brain and Cognitive Sciences, Massachusetts Institute of Technology, Cambridge, Massachusetts \\ 02139 and ${ }^{2}$ Department of Biology and Center for Complex Systems, Brandeis University, Waltham, Massachusetts \\ 02254
}

It is well known that visual cortical neurons respond vigorously to a limited range of stimulus orientations, while their primary afferent inputs, neurons in the lateral geniculate nucleus (LGN), respond well to all orientations. Mechanisms based on intracortical inhibition and/or converging thalamocortical afferents have previously been suggested to underlie the generation of cortical orientation selectivity; however, these models conflict with experimental data. Here, a 1:4 scale model of a $1700 \mu \mathrm{m}$ by $200 \mu \mathrm{m}$ region of layer IV of cat primary visual cortex (area 17) is presented to demonstrate that local intracortical excitation may provide the dominant source of orientation-selective input. In agreement with experiment, model cortical cells exhibit sharp orientation selectivity despite receiving strong iso-orientation inhibition, weak cross-orientation inhibition, no shunting inhibition, and weakly tuned thalamocortical excitation. Sharp tuning is provided by recurrent cortical excitation. As this tuning signal arises from the same pool of neurons that it excites, orientation selectivity in the model is shown to be an emergent property of the cortical feedback circuitry. In the model, as in experiment, sharpness of orientation tuning is independent of stimulus contrast and persists with silencing of ON-type subfields. The model also provides a unified account of intracellular and extracellular inhibitory blockade experiments that had previously appeared to conflict over the role of inhibition. It is suggested that intracortical inhibition acts nonspecifically and indirectly to maintain the selectivity of individual neurons by balancing strong intracortical excitation at the columnar level.

[Key words: visual cortex, orientation selectivity, computational neuroscience, recurrent excitation, intracortical inhibition, cortical circuits]

Visual cortical orientation selectivity is one of the most thoroughly investigated receptive field properties in all of neocortex; however, its underlying neural mechanisms have yet to be fully illuminated (see Ferster and Koch, 1987; Martin, 1988). Currently favored models rely on either oriented convergence of

\footnotetext{
Received Jan. 9, 1995; revised Mar. 3, 1995; accepted Mar. 8, 1995.

This work supported by the McDonnell-Pew Center for Cognitive Neuroscience at MIT; NIH Grants MH-10671, EY-06363, EY-07023; and a grant of High Performance Computing time from the Project Scout at MIT-LCS, sponsored under ARPA Contract MDA 972-92-J-1032.

Correspondence should be addressed to David C. Somers, Department of Brain and Cognitive Sciences, MIT, E25-618, 45 Carleton Street, Cambridge, MA 02139.

Copyright $(1995$ Society for Neuroscience $0270-6474 / 95 / 155448-18 \$ 05.00 / 0$
}

thalamocortical inputs (feedforward excitation) or a combination of intracortical inhibition and thalamocortical convergence. However, "feedforward" and "inhibitory" models (see Fig. 1) are inconsistent with key pieces of physiological data and neglect the effects of connections from intracortical excitatory neurons, which provide the majority of synapses onto cells in all cortical layers (LeVay and Gilbert, 1976; Peters and Payne, 1993; Ahmed et al., 1994).

Feedforward models suggest that cortical neurons obtain orientation selectivity from elongated patterns of converging LGN inputs (see Fig. 1a) (Hubel and Wiesel, 1962; Ferster, 1987). Experiments qualitatively support this idea; on average, cortical simple cell subfields are elongated along an axis parallel to the preferred response orientation (Jones and Palmer, 1987; Chapman et al., 1991). But for many simple cells subfield length-to-width ratios (aspect ratios) are quantitatively insufficient to account for the sharp orientation selectivity exhibited (Watkins and Berkley, 1974; Jones and Palmer, 1987). Reports of low mean aspect ratios (Chapman et al., 1991; Pei et al., 1994) are also inconsistent with feedforward models of orientation selectivity. Weakly biased feedforward inputs can be sharpened by using high firing thresholds (the "iceberg" effect; Creutzfeldt et al., 1974b), but this mechanism incorrectly predicts broadening of orientation tuning with increasing stimulus contrast (Sclar and Freeman, 1982; Wehmeier et al., 1989). Pure feedforward models also cannot account for the loss of orientation selectivity observed under iontophoresis of bicuculline, a $\mathrm{GAB} \Lambda_{\mathrm{A}}$ antagonist, which reduces inhibition over a localized population of cortical neurons (Sillito, 1975; Tsumoto et al., 1979; Sillito et al., 1980).

Mechanisms that utilize shunting ("divisive") inhibition (e.g., Koch and Poggio, 1985; Carandini and Heeger, 1994), hyperpolarizing ("subtractive") inhibition at nonpreferred orientations (see Fig. 1b) (e.g., Wehmeier et al., 1989; Wörgotter and Koch, 1991), and/or inhibition between spatially overlapping cells with opposite contrast polarity (e.g., ON-OFF) (Heggelund, 1981) can sharpen tuning in cells that have mildly oriented thalamocortical inputs, can produce contrast-invariant orientation tuning, and can account for bicuculline-induced tuning loss. However, inhibitory models are inconsistent with other experimental data. Shunting inhibition plays little role in orientation selectivity (Douglas et al., 1988; Berman et al., 1991; Dehay et al., 1991; Ferster and Jagadeesh, 1992), and silencing ON-type subfields does not disrupt sharp orientation selectivity (Schiller, 1982; Sherk and Horton, 1984). Inhibitory postsynaptic potentials (IPSPs) are evoked strongly by stimuli presented at the preferred orientation, while cross-orientation stimuli evoke weak IPSPs 


\section{Feedforward Inhibitory Recurrent}

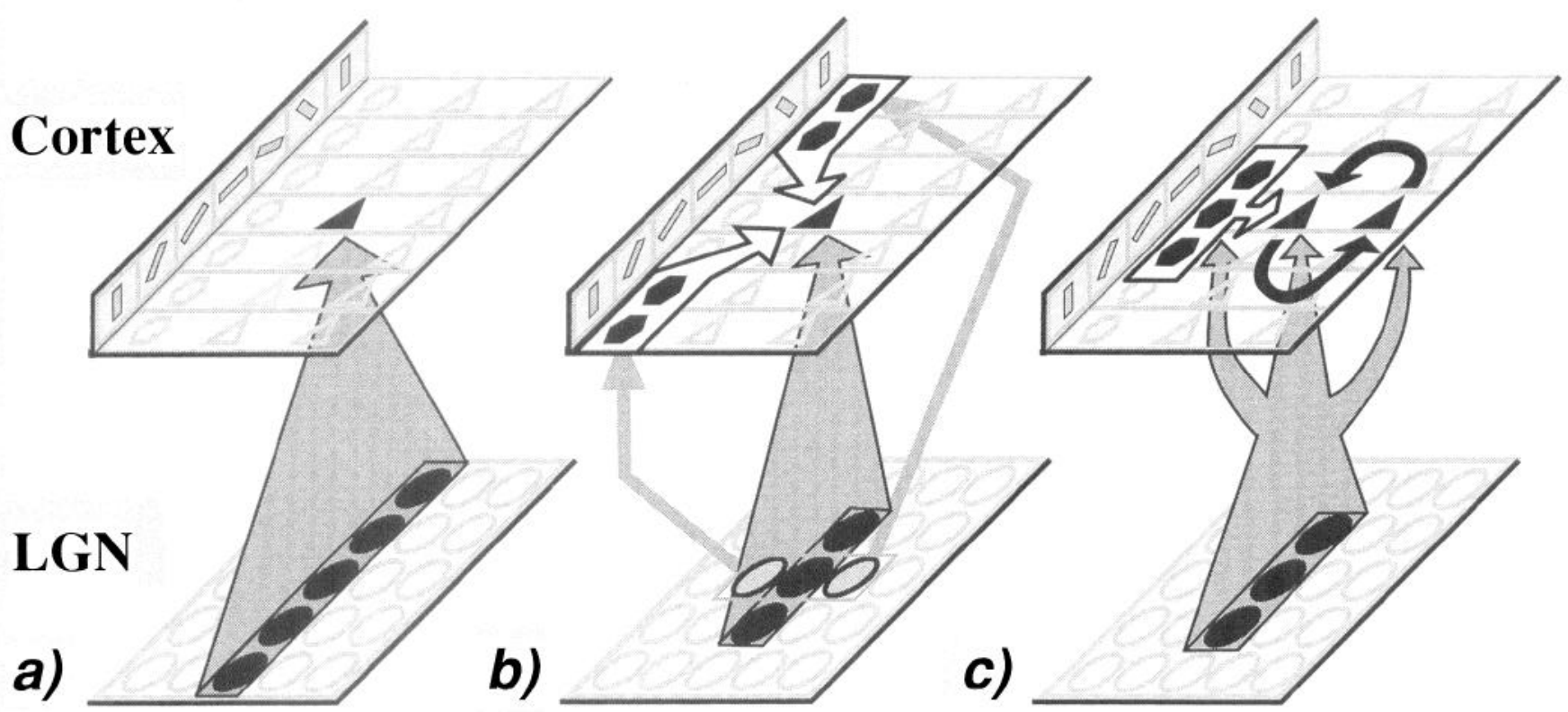

Figure 1. Models of visual cortical orientation selectivity. $a$, In feedforward models all "first-order" cortical neurons (triangle, excitatory; hexagon, inhibitory) receive converging input (gray arrow) from a population of LGN neurons that cover a strongly oriented region of visual space. The bandwidth or sharpness of a cortical cell's orientation tuning is determined by the aspect ratio of its LGN projection. $b$, Many inhibitory models employ a mild feedforward bias to establish the initial orientation preference of cortical neurons and utilize inhibitory inputs (white arrows), from cortical neurons preferring different orientations, to suppress nonpreferred responses. Here, we present a model, $c$, in which recurrent cortical excitation (black arrows) among cells preferring similar orientations, combined with iso-orientation inhibition from a broader range of orientations, integrates and amplifies a weak thalamic orientation bias, which is distributed across the cortical columnar population.

(Ferster, 1986; Douglas et al., 1991a; for a differing view, see Pei et al., 1994). Such inhibitory tuning conflicts with crossorientation inhibitory models (Bishop et al., 1973; Morrone et al., 1982), and strong iso-orientation suppression poses problems even for models that use other forms of hyperpolarizing inhibition to sharpen thalamocortical input (e.g., Wörgotter and Koch, 1991). Furthermore, recent results from our laboratory conflict with all orientation models that rely heavily on direct inhibitory input. Whole-cell, intracellular blockade of inhibition had negligible effect on sharpness of orientation tuning of blocked cells (Nelson et al., 1994). These results also appear to conflict with reports that orientation tuning can be abolished by bicuculline-induced extracellular inhibitory blockade (Sillito et al., 1980; Nelson, 1991).

Here, we demonstrate that this apparent paradox can be resolved by considering the effects the two inhibitory blockades have on the tuning of cortical excitatory inputs. Our computer simulations also demonstrate that local, recurrent cortical excitation can generate sharp, contrast-invariant orientation tuning in circuits that have strong iso-orientation inhibition and weakly oriented thalamocortical excitation (see Fig. 1c). This model primarily addresses the circuitry within a single cortical "hypercolumn"; effects of adding long-range cortical connections to this circuitry are addressed elsewhere (Somers et al., 1994).

Some of these results have been published in preliminary form (Somers et al., 1993, 1995).

\section{Materials and Methods}

\section{The model}

A model visual cortical circuit was implemented in largescale computer simulations. The model represented cortical layer IV circuitry under a $1700 \mu \mathrm{m}$ by $200 \mu \mathrm{m}$ patch of cortical surface and was composed of more than 3000 spiking neurons with over 180,000 synapses. Cortical excitatory and inhibitory neurons were modeled separately using intracellular parameters from regular-spiking and fast-spiking neurons (Connors et al., 1982; McCormick et al., 1985). Retinal and geniculate cell populations spanning a $4^{\circ}$ by $4^{\circ}$ monocular patch of the central visual field were also represented. The model was organized as three sequential layers: ON and OFF retinal ganglion cells, ON and OFF lateral geniculate nucleus neurons, and simple cells in layer IV of cortical area 17. Oriented flashed bar stimuli were presented to the retinal cells and the response properties of cortical cells were studied.

Retinal ganglion cells. Four hundred forty-one $\mathrm{ON}$ and 441 OFF retinal ganglion cells (RGCs) were configured as two 21 by 21 arrays of neurons with center-surround receptive field antagonism. Center fields were $30^{\prime}$ wide and the center-to-center spacing between neighboring receptive fields was $12^{\prime}$ of visual angle. The ganglion cell model utilized was developed elsewhere and has been shown to produce realistic temporal responses to visual stimuli (Wehmeier et al., 1989; Wörgotter and Koch, 1991). We confirmed that our implementation yielded responses to flashed stimuli that qualitatively matched sustained and transient response components of X-type cells (Rodieck and Stone, 1965). Average firing rates were generated by subtracting surround responses from center responses. Each retinal sub- 
field response was generated by a spatiotemporal convolution of the subfield profile with the image

$$
\begin{aligned}
& R(x, y, t)= \\
& \int_{0}^{t} \int_{-\infty}^{\infty} \int_{-\infty}^{\infty} F\left(x^{\prime}, y^{\prime}\right) G\left(t^{\prime}\right) I\left(x-x^{\prime}, y-y^{\prime}, t-t^{\prime}\right) \cdot d x^{\prime} d y^{\prime} d t^{\prime} .
\end{aligned}
$$

Center and surround spatial profiles were modeled as twodimensional Gaussians, with a common space constant for both dimensions:

$$
F(x, y)=\left(K / 2 \pi \sigma^{2}\right) \exp \left(-\left(x^{2}+y^{2}\right) / 2 \sigma^{2}\right),
$$

where $\sigma_{\text {center }}=10.6^{\prime}, \sigma_{\text {surround }}=31.8^{\prime}$, and $K_{\text {center }} / K_{\text {surround }}=$ 17/16 (Linsenmeier et al., 1982). This yielded a center width of 30' (Peichl and Wässle, 1979). Beyond $3 \sigma$ the fields were set to zero. The temporal profile of each field was given by

$$
G(t)=(1 / \tau) \exp (-t / \tau),
$$

where $\tau_{\text {center }}=10 \mathrm{msec}$ and $\tau_{\text {surround }}=20 \mathrm{msec}$ (Richter and Ullman, 1982).

$\mathrm{ON}$ and OFF retinal ganglion cell responses were given by

$$
\mathrm{ON}(x, y, t)=\left[R_{\text {center }}(x, y, t)-R_{\text {surround }}(x, y, t-\delta)\right]^{+}
$$

and

$$
\begin{gathered}
\mathrm{OFF}(x, y, t)=\left[(2-\text { baseline })-R_{\text {center }}(x, y, t)+R_{\text {surround }}(x,\right. \\
y, t-\delta)]^{+},
\end{gathered}
$$

respectively, where $[\cdot]^{+}=\max (\cdot, 0)$, and $\delta$ is a 3 msec delay between center and surround field responses (Enroth-Cugell et al., 1983). Baseline was defined as the response of an ON cell to uniform background stimuli. Addition of this term to OFF cells ensured that $\mathrm{ON}$ and $\mathrm{OFF}$ cells exhibited the same spontaneous activity levels in response to a uniform field.

Input stimuli. The stimuli used were oriented dark bars flashed onto a uniform light background. At the preferred orientation, stimulus dimensions of $1^{\circ} \times 3^{\circ}$ optimally excited the cortical cell population. In vivo, longer stimuli can yield either reduced responses (length tuning) or sharper tuning (for non-length-tuned cells); however, the model did not address these longer-range effects. 16 different bar orientations spanning $180^{\circ}\left(11.25^{\circ}\right.$ difference between stimuli) were used to construct orientation tuning curves. Note that flashed bars which differ in orientation by $180^{\circ}$ are identical stimuli. For all orientations, stimuli were centered on the RF center of the OFF subfields of cells. Stimulus contrast was varied between $5 \%$ and $100 \%$. Stimulus luminance values were chosen so that model LGN cells firing rates matched experimental values for the given contrast (Kaplan et al., 1987; Chino and Kaplan, 1988; Bonds, 1993). Each stimulus trial consisted of three phases: a short presentation (50-150 $\mathrm{msec}$ ) of the uniform background, flashed presentation of the bar stimulus on the background for $500 \mathrm{msec}$ or $250 \mathrm{msec}$, and then a return to the uniform background $(50-150 \mathrm{msec})$. Only the spikes elicited by the bar stimulus $(500 \mathrm{msec}$ or $250 \mathrm{msec}$ time window) were included in calculation of orientation tuning curves. As stimulus duration was found to have negligible effect on tuning curve properties, short-duration stimuli were used to construct the final set of orientation tuning curves due to the computational speed advantage.

Lateral geniculate cells. Four hundred forty-one $\mathrm{ON}$ and 441 OFF LGN cells were represented by two 21 by 21 arrays of neurons with center-surround antagonism. There was oneto-one correspondence between RGCs and LGN cells, so that the response of each RGC was uniquely passed on to onc LGN cell of the same center polarity (center field diameter, 30'; center-to-center separation, 12'). Experimental reports suggest that many LGN neurons exhibit mild orientation biases (Vidyasagar and Urbas, 1982; Soodak et al., 1987; Shou and Leventhal, 1989). As the model utilized circularly symmetric receptive fields, these biases were not incorporated. However, the effects of LGN receptive field biases are likely similar to the effects of oriented converging thalamocortical inputs, which were utilized in the model. Firing rates of RGCs were used to generate spikes in LGN cells using a Poisson process. The probability that an LGN neuron would spike in a fixed small $(0.25 \mathrm{msec})$ time interval, $\Delta t$, was given by

$$
p(x, y, t)=k \cdot \Delta t \cdot \operatorname{RGC}\left(t-\delta_{\text {syn }}\right),
$$

where $k=1 / 1000 \mathrm{sec} /\left(\mathrm{msec}\right.$ spikes), and $\delta_{\mathrm{syn}}$ is the synaptic delay between the retinal and LGN cell. In this model, the term "synaptic delay" refers to the time between somatic generation of a presynaptic spike and somatic receipt of a postsynaptic potential. Each synaptic delay was chosen uniquely from a normal distribution with mean $3.0 \mathrm{msec}$ and variance $1.0 \mathrm{msec}$.

LGN contrast response functions (Chino and Kaplan, 1988; Bonds, 1993) were fit by the function

$$
R(c)=S+25 \log _{10}(c),
$$

where $S=15$ spikes per second (sp/s) is the spontaneous firing rate (Kaplan et al., 1987). Although the retinal model provided accurate temporal response properties, the absolute response rates it produced did not match this contrast response function. To compensate, stimuli luminance values were chosen to yield the appropriate LGN responses. That is, the term "stimulus contrast" here refers to the LGN response produced rather than to the bar and background luminance values used. This permitted generation of realistic LGN cell responses without full elaboration of the circuitry underlying those responses. As our focus here is on cortical circuitry, not thalamic circuitry, this simplification seems justified.

Cortical circuitry. The model addresses the parallel generation of orientation selectivity in cortical neurons that receive direct thalamic input. Specifically, the circuit represents layer IV simple cells that lie under a $1700 \mu \mathrm{m}$ by 200 $\mu \mathrm{m}$ patch of visual cortical area 17 of the cat. This small cortical area contains orientation columns representing a full set of preferred orientations (e.g., a hypercolumn), as well as neighboring columns. The model implemented 2205 cortical neurons, of which $20 \%$ were inhibitory and the rest 
excitatory (Gabbott and Somogyi, 1986). In cat area 17, estimates indicate that between 14,000 and 26,000 neurons reside in layer IV under $1 \mathrm{~mm}^{2}$ of cortical surface (Beaulieu and Colonnier, 1983; Peters and Yilmaz, 1993). Therefore, the model was a $1: 2.2$ to $1: 4$ scale representation of this cortical volume. This scale was chosen primarily due to computational constraints. Synaptic connections and delays were fixed for the defined network, and did not vary with parameter searches or input stimuli. In total, the network contained over 180,000 synapses.

Cortical neurons were organized into 21 orientation columns, spanning the length dimension of the cortical patch. Each column consisted of 84 excitatory and 21 inhibitory neurons. An initial orientation structure was generated in cortex by providing orientation-biased converging LGN input to each cortical column. The preferred orientation varied monotonically across columns, with neighboring columns differing by $15^{\circ}$ in preferred orientation. Twelve columns represented a full $180^{\circ}$ of preferred orientations. Although LGN inputs created a columnar orientation bias, many cortical cells received poorly oriented or unoriented LGN input and no cortical cell obtained sharp tuning (e.g., $20^{\circ}$ halfwidth at half-amplitude) solely on the basis of LGN input.

Cortical neurons received synaptic inputs from lateral geniculate (excitatory), cortical excitatory, and cortical inhibitory neurons. Cortical simple cell receptive field structure was established by segregation of ON and OFF LGN inputs into three subfields (ON-OFF-ON). In the model, thalamocortical connections were defined by a two-stage process. First, boundary dimensions of each subfield were established, and then LGN cells were chosen from uniform distributions within the boundaries. Mean experimental values for simple cell subfield widths in the central $6^{\circ}$ of the visual field are approximately $1^{\circ}$ (Palmer and Davis, 1981; Heggelund, 1986). In the model, each subfield template was $1^{\circ}$ wide with center-to-center separation of $1^{\circ}$. Across cortical cells, subfield lengths varied uniformly between $1^{\circ}$ and $3^{\circ}$, with a mean of $2^{\circ}$. Thus, subfield aspect ratios varied between 1:1 (unoriented) and 3:1 (moderately oriented). The mean subfield aspect ratio (2:1) used in the model closely approximates the mean aspect ratio (1.7:1) reported from intracellular experiments in cats (Pei et al., 1994), and the aspect ratio of the combincd LGN inputs to a cortical column (3:1) matches the experimental value obtained in ferrets (Chapman et al., 1991). These aspect ratio values underestimate the range reported from extracellular recordings (Watkins and Berkley, 1974; Jones and Palmer, 1987). Extracellular recordings likely overestimate aspect ratios since these recordings reflect a cell's output (after any sharpening from the firing threshold and cortical inputs) rather than a cell's input. Nevertheless, it is quite possible that cortex contains some neurons that receive thalamic input sufficient to support sharp orientation tuning. Such cells were excluded from the present model to make clearer the demonstration of a cortical tuning mechanism.

In the cat, layer IV cortical excitatory neurons receive a total of between 3000 (Peters and Payne, 1993) and 6000 (Beaulieu and Colonnier, 1985; Anderson et al., 1994b) synapses. Cortical inhibitory neurons, due to their lower cell surface areas, are likely to receive substantially fewer synapses. Anatomical estimates suggest that thalamocortical synapses comprise between 4\% (Garey and Powell, 1971; Hornung and Garey, 1981; Winfield and Powell, 1983; LeVay, 1986; Peters and Payne, 1993; Ahmed et al., 1994). and 24\% (LeVay and Gilbert, 1976; Einstein et al., 1987) of all synapses received by layer IV neurons. In the model, cortical excitatory and inhibitory neurons received 24 and 16 LGN synapses, respectively, each receiving an equal number of $\mathrm{ON}$ and $\mathrm{OFF}$ inputs. This value was chosen for computational efficiency. Thus, the model represents between 1/5th (Peters and Payne, 1993) and 1/60th of the thalamic synapses onto layer IV cortical neurons. Since the model explores a cortical excitatory tuning mechanism, it is more conservative to choose a higher estimate for the proportion of total synapses provided by LGN inputs. In defining the remaining synapses, the model assumes LGN inputs contribute $20 \%$ of all synapses.

Cortical inhibitory synapses comprise approximately 16 $21 \%$ of total cortical synapses (Beaulieu and Colonnier, 1985; Anderson et al., 1994b). An estimated 8-13\% of GABAergic synapses target other GABAergic neurons (Beaulieu and Somogyi, 1990; Kisvàrday et al., 1993). The model assumed that cortical excitatory and inhibitory neurons respectively receive $20 \%$ and $10 \%$ of their synapses from cortical inhibitory neurons. Scaling relative to the number of LGN inputs in the model yields 24 and 8 inhibitory synapses onto excitatory and inhibitory cells, respectively. Model cortical excitatory cells provided 36 and 56 synapses onto each excitatory and inhibitory neuron, respectively. Thus, in agreement with anatomical estimates, model cortical excitatory cells contributed the largest number of synaptic inputs to layer IV neurons (Martin, 1988; Peters and Payne, 1993; Ahmed et al., 1994). The 36 excitatory-excitatory synapses represent half of the scaled number suggested by anatomy. This reduction was done to mitigate the effects of positive feedback (see Discussion); with this reduced number of synapses, cortical inputs still contributed the largest component of the excitatory postsynaptic potentials (EPSPs) at the preferred orientation.

To generate iso-orientation excitation and inhibition, cortical excitatory and inhibitory inputs were chosen from normal distributions, each with maximal connectivity probability within the cortical column of the postsynaptic cell. Inhibitory inputs were drawn from a broader range of orientations than the excitatory inputs $\sigma_{\mathrm{INHIB}}=60^{\circ}, \sigma_{\mathrm{EXCIT}}=7.5^{\circ}$. The gaussian distributions were clipped so that cortical cells differed by no more than $60^{\circ}$ in preferred orientation from that of its postsynaptic targets. Thus, inhibitory inputs had a range of $\pm 60^{\circ}(\sim \pm 350 \mu \mathrm{m})$ while excitatory inputs had an effective range of $\pm 15^{\circ}(\sim \pm 100 \mu \mathrm{m})$, with approximately $32 \%$ of excitatory inputs coming from neighboring columns. These orientation ranges are similar to values re- 
ported from cross-correlation studies (Michalski et al., 1983; Hata et al., 1988). Cells received no more than one synapse from any single cell. Although many cortical neurons have axons that travel several millimeters horizontally across cortex (Gilbert and Wiesel, 1983), cortical neurons appear to synapse most densely very near their cell bodies (Szentàgothai, 1965; Gilbert and Wiesel, 1983; Kisvàrday et al., 1985; White, 1989; Anderson et al., 1994a). In this article, we addressed only local, short-range $(<500 \mu \mathrm{m})$ intracortical connections. Effects of long-range connections are addressed elsewhere (Somers et al., 1994).

In the model both intracortical and thalamocortical excitatory synapses had maximal synaptic conductances of $3 \mathrm{nS}$. Betwecn rest and threshold voltages, single EPSP amplitudes were approximately $0.8 \mathrm{mV}$. In vitro recordings suggest single EPSP amplitude values of $0.14 \pm 0.09 \mathrm{mV}$ (Komatsu et al., 1988), 0.05-2.0 mV (Mason et al., 1991), and 0.19-3.6 $\mathrm{mV}$ (Smetters and Nelson, 1993). Thus, single FPSPs in the model are consistent with the higher end of experimental values. Since the model was forced to underrepresent the total number of synapses (due to computational constraints), utilizing the higher range of unitary PSP amplitudes seems reasonable. Visual cortical inhibitory synaptic conductances have been suggested to be stronger than excitatory conductances (Komatsu et al., 1988). Model inhibitory synapses had maximal synaptic conductances of $5 \mathrm{nS}$. At rest, unitary IPSP amplitudes in the model were $0.2 \mathrm{mV}$, while near threshold unitary IPSP amplitudes were $0.58 \mathrm{mV}$. Komatsu et al. (1988) report at rest, IPSP amplitudes were $0.09 \pm$ $0.05 \mathrm{mV}$, while with depolarizing current amplitudes could reach a few $\mathrm{mV}$. The effects of other maximal conductance values were also explored (see Fig. 7).

Each synapse had a randomly chosen synaptic delay, which represents the total soma-to-soma time delay for spike-evoked PSPs. Synaptic delays were chosen from zerobounded normal distributions. Intracortical (excitatory and inhibitory) synapses had mean delays of $3 \mathrm{msec}$ with a variance of $1 \mathrm{msec}$. These values may slightly overestimate experimental estimates. Since the tuning mechanism investigated here depends on activation of cortical feedback, we chose to "err" on the side of longer delays. No ill effects were observed with shorter delays. Thalamocortical synapses unto cortical excitatory and inhibitory cells had mcan delays of $10 \mathrm{msec}$ and $5 \mathrm{msec}$ with variances of $5 \mathrm{msec}$ and $3 \mathrm{msec}$, respectively. The differences in thalamocortical timing were introduced in light of earlier reports that relative timing of feedforward excitation and inhibition had a significant effect on net (feedforward plus feedback) inhibitory and excitatory responses evoked (Douglas and Martin, 1991). Freund et al. (1985) reported highly myelinated LGN axonal projections that preferentially targeted the somas of inhibitory visual cortical neurons. Douglas and Martin (1991) suggested that this input may provide fast, feedforward inhibition. In the model these synaptic delay values were not varied systematically, but sharp orientation tuning persisted when the relative timing difference was eliminated (see Results and Discussion). The primary utility of the timing difference was to reduce the net inhibition required for sharp tuning.

Cortical cell model. Excitatory and inhibitory cortical neurons were modeled separately using experimentally reported input resistances, membrane time constants, and firing characteristics of regular-spiking (RS) and fast-spiking (FS) neurons (Connors et al., 1982; McCormick et al., 1985). Each cortical neuron was modeled as a single voltage compartment in which the membrane potential, $V_{i}$, was given by

$$
\begin{aligned}
C_{m} \frac{d V_{i}(t)}{d t}= & -\sum_{j=1}^{k} g_{j i}\left(t \quad t_{j i}\right)\left(V_{i}(t)-E_{\mathrm{EXCII}}\right) \\
& -\sum_{j=k+1}^{k+1} g_{j i}\left(t-t_{j i}\right)\left(V_{i}(t)-E_{\mathrm{LNHIB}}\right) \\
& -g_{\mathrm{LEAK}}\left(V_{i}(t)-E_{\mathrm{LEAK}}\right) \\
& -g_{\mathrm{AHP}}\left(t-t_{\mathrm{SPIKE}}\right)\left(V_{i}(t)-E_{\mathrm{AHP}}\right),
\end{aligned}
$$

where the synaptic conductances generated at each postsynaptic cell $i$ by the spiking of each presynaptic cell $j$ were given by

$$
g_{j i}(t)=\bar{g}_{j i} \sum_{p}^{S_{j}}\left(t-t_{p}\right)\left(e / \tau_{\text {peak }}\right) \exp \left(-\frac{t-t_{p}}{\tau_{\text {peak }}}\right) .
$$

$t_{j i}$ and $\bar{g}_{j i}$ describe the delay and maximal conductance change produced for the synapse between cell $j$ and cell $i$ (see above). Spike-evoked conductance changes reached their maximal values at $\tau_{\text {PEAK }}$, which was $1 \mathrm{msec}$ for excitatory synapses, $2 \mathrm{msec}$ for inhibitory synapses, and $2 \mathrm{msec}$ for afterhyperpolarization. $t_{\mathrm{p}}$ represented the time of each spike (described by the set $S_{j}$ ) of presynaptic cell $j . \mathrm{Na}^{+}-$ mediated spike dynamics were replaced by a time-varying firing threshold. When the membrane potential exceeded threshold, a spike was recorded, the spike threshold was elevated, and a hyperpolarizing conductance was activated. Baseline spike threshold value was $-55 \mathrm{mV}$. This computational level of neuronal representation permits realistic consideration of both intracellular and network phenomena.

The numbers of excitatory and inhibitory synapses received by cell $i$ were $k$ and $l$, respectively. Excitatory synaptic effects were implemented as linear conductance changes, neglecting the effects of NMDA receptor-mediated conductances. The effective reversal potential, $\mathrm{E}_{\mathrm{Excr}}$, was $0 \mathrm{mV}$. $\mathrm{GABA}_{\mathrm{A}}$-type inhibitory effects were modeled as linear conductance changes at $\mathrm{Cl}^{-}$channels $\left(E_{\mathrm{INHIB}}=-70 \mathrm{mV}\right)$. Slower $\mathrm{GABA}_{\mathrm{B}}$ inhibition was not incorporated. Afterhyperpolarization effects were spike triggered (with delay $t_{\mathrm{SPIKE}}=1 \mathrm{msec}$ ) and $\mathrm{K}^{+}$mediated $\left(E_{\mathrm{AHP}}=-90 \mathrm{mV}\right)$. The leak reversal potential, $E_{\mathrm{LEAK}}$, was $-65 \mathrm{mV}$. Parameters $C_{m}, g_{\mathrm{LEAK}}$, and $g_{\mathrm{AHP}}$ were membrane capacitance, leakage conductance, and after hyperpolarization conductance. Regular spiking (excitatory) neurons had parameter values of $C_{m}=0.5 \mathrm{nF}, g_{\mathrm{LEAK}}=25 \mathrm{nS}$, and $g_{\mathrm{AHP}}=40 \mathrm{nS}$. Fast-spiking (inhibitory) neurons had parameter values of $C_{m}=0.2 \mathrm{nF}, g_{\mathrm{LEAK}}=20 \mathrm{nS}$, and $g_{\mathrm{AHP}}=$ $20 \mathrm{nS}$. These values correspond to membrane time constants, 
$\tau_{m}$, of $20 \mathrm{msec}$ for excitatory neurons and $10 \mathrm{msec}$ for inhibitory neurons. Absolute refractory periods were $3.0 \mathrm{msec}$ and $1.6 \mathrm{msec}$ for RS and FS neurons. Relative refractory periods were generated by time-varying thresholds that pulsed up 10 $\mathrm{mV}$ on a spike and exponentially decayed to baseline with a $10 \mathrm{msec}$ time constant. This roughly approximates the refractory effects of $\mathrm{Na}^{+}$channel inactivation. These parameters yielded approximate fits to experimental frequency versus current plots for cortical neurons (McCormick et al., 1985). With strong injected current RS ncurons can firc in excess of $300 \mathrm{~Hz}$; FS neurons in excess of $600 \mathrm{~Hz}$. The above parameters were fixed and their effects on network performance were not explored. Adaptation properties of regular spiking neurons were not addressed.

\section{Pharmacological blockade simulations}

2-Amino-4-phosphonobutyrate (APB), a glutamate analog, when injected into the retina of cats or monkeys silences activity of $\mathrm{ON}$ retinal bipolar cells and of the subsequent $\mathrm{ON}$ pathway of $\mathrm{ON}$ retinal ganglion cells, ON LGN cells, and ON subfields of cortical simple cells (Schiller, 1982; Horton and Sherk, 1984; Sherk and Horton, 1984). OFF-channel cells exhibit normal center-surround antagonism. Significantly, APB injection does not disrupt cortical orientation tuning. The effects of APB on the model circuit were addressed by silencing activity of all $\mathrm{ON}$-center retinal ganglion and LGN cells in the model. This was achieved by setting all ON retinal ganglion responses to zero. OFF cell activity was not altered.

Iontophoresis of bicuculline methiodide, a $\mathrm{GABA}_{\mathrm{A}}$ antagonist, has been shown to disrupt and, at high dosage, abolish orientation selectivity (Sillito, 1975; Tsumoto et al., 1979; Sillito et al., 1980; Nelson, 1991). In most cases long ejection times are required, implying that bicuculline must diffuse across a local population of neurons before selectivity is lost. In the model, the effects of bicuculline have been explored by reducing the maximal synaptic inhibitory conductances onto all cells within a single cortical column $(n=84$ excitatory cells and 21 inhibitory cells). High hicuculline doses were represented by $50 \%$ reduction of $\bar{g}_{\text {CTX-N }}$.

In recent experiments, our laboratory has silenced $\mathrm{Cl}^{-}-$and $\mathrm{K}^{+}$-mediated inhibition in single visual cortical neurons in vivo by whole-cell administration of cesium fluoride (CsF) and 4,4'diisothiocyanatostilbene-2,2'-disulfonic acid (DIDS) (or picrotoxin) with no ATP and no GTP (Nelson et al., 1994). The blockade was often accompanied by injection of a mild hyperpolarizing current to compensate for the increased spontaneous firing rates that occurred as a side effect of the blockade. The current level was held fixed for all stimulus orientations. In the model, the effects of CsF-DIDS were addressed by setting maximal inhibitory synaptic conductances, $\bar{g}_{\mathrm{CTX} \cdot \mathrm{IN}}$, to 0 , and by reducing maximal afterhyperpolarizing conductances by $80 \%$. $g_{\text {AHP }}$ values were not varied systematically, but a residual, nonzero $g_{\text {AHP }}$ was deemed desirable as a means of providing a degree of repolarization after a spike. This was performed on only a single cell per simulation. The effects of the hyperpolarizing current were explored in the model; empirically a $-0.3 \mathrm{nA}$ current was chosen for the full orientation studies. DIDS cells were also tested without current injection.

\section{Data collection and analysis}

Stimulus evoked spikes were collected over a time window equal to the stimulus duration, $\Delta t_{\text {duration }}$ (window delay $20 \mathrm{msec}$ ).
Orientation response curves were generated by summing each cell's response over several (10-18) presentations of each of 16 stimulus orientations $\left(11.25^{\circ}\right.$ resolution). Sharpness of orientation tuning was quantified by measuring the half-width of the tuning curve at half of its peak amplitude. Half-width at halfamplitude (HW) measures of tuning were computed by interpolation between data points on the orientation tuning curves. HW measures were computed for all cells in the $0^{\circ}$ column. For the extensive parameter search used to construct Figure 7, responses of all excitatory neurons were summed to generate a mean orientation response curve.

Synaptic conductance values were computed by summing Equation 9 for all spikes received. These values were summed with the leak conductance to obtain the net conductance. Levels of summed postsynaptic potentials received by a cell were computed by

$$
\begin{aligned}
& \text { Avg. } \operatorname{PSP}_{i}=\left[\sum_{j=1}^{k} S_{j} \int_{0}^{\infty} g(t)\left(\bar{V}_{i}-E_{\text {channel }}\right) d t\right] \\
& \div\left[g_{\text {leak }} \Delta t_{\text {duration }}\right] \text {, }
\end{aligned}
$$

where $\left(\bar{V}_{i}-E_{\text {channel }}\right)$ represents the average driving force on a synaptic channel class (i.e., inhibitory). $\bar{V}_{i}$ was approximated by the baseline spike threshold $(-55 \mathrm{mV})$. This approximation is reasonably accurate for preferred stimulus orientations; however, it overestimates IPSP levels for nonpreferred orientations. Since low experimental values of cross-orientation IPSP levels represent an important model constraint (Ferster, 1986; Douglas et al., 1991a), we made the conservative decision to err on the side of overestimation of these values.

\section{Simulation software}

Numerical simulations of the cortical circuit were implemented in the SPIKETIME neural simulation package (Somers, unpublished observations) and run on the CM-5 Connection Machine (Thinking Machines, Inc.). SPIKETIME incorporates published computer code (Press et al., 1992) for fourth-order, Runge-Kutta numerical integration of systems of ordinary differential equations. Integration time step was $0.25 \mathrm{msec}$, which provided accuracy to $0.125 \mathrm{msec}$.

\section{Results}

\section{Normal response properties}

Cortical cells exhibited low spontaneous firing rates of 0.5 spikes/sec (sp/s) for excitatory cells and $4 \mathrm{sp} / \mathrm{s}$ for inhibitory cells, due to spontaneous LGN firing rates (e.g., responses to uniform background stimuli). Orientation tuning properties were thoroughly investigated for neurons in the central $0^{\circ}$ cortical column. Both excitatory and inhibitory neurons were sharply selective for stimuli oriented at $0^{\circ}$. Mean half-width at half-amplitude (HW) of the orientation tuning curves for all cells in the column was $17.7^{\circ}(n=105)$. Mean HW tuning of excitatory cells $(n=84)$ was $17.1^{\circ} \pm 0.6^{\circ}( \pm \mathrm{SD})$, and mean HW tuning of inhibitory cells $(n=21)$ was $20.5^{\circ} \pm 0.7^{\circ}( \pm$ SD). The sharpness of tuning is consistent with typical physiological values for cortical simple cells (Watkins and Berkley, 1974; Orban, 1984). Neurons in other columns exhibited similarly sharp tuning for other stimulus orientations. Figure $2 a$ displays an intracellular trace of a typical model cortical excitatory cell in response to flashed bar stimuli oriented at $0^{\circ}, 22.5^{\circ}, 45^{\circ}$, and $90^{\circ}$. As is true for all cells in the column, this cell is sharply selective for the $0^{\circ}$ stimulus. 

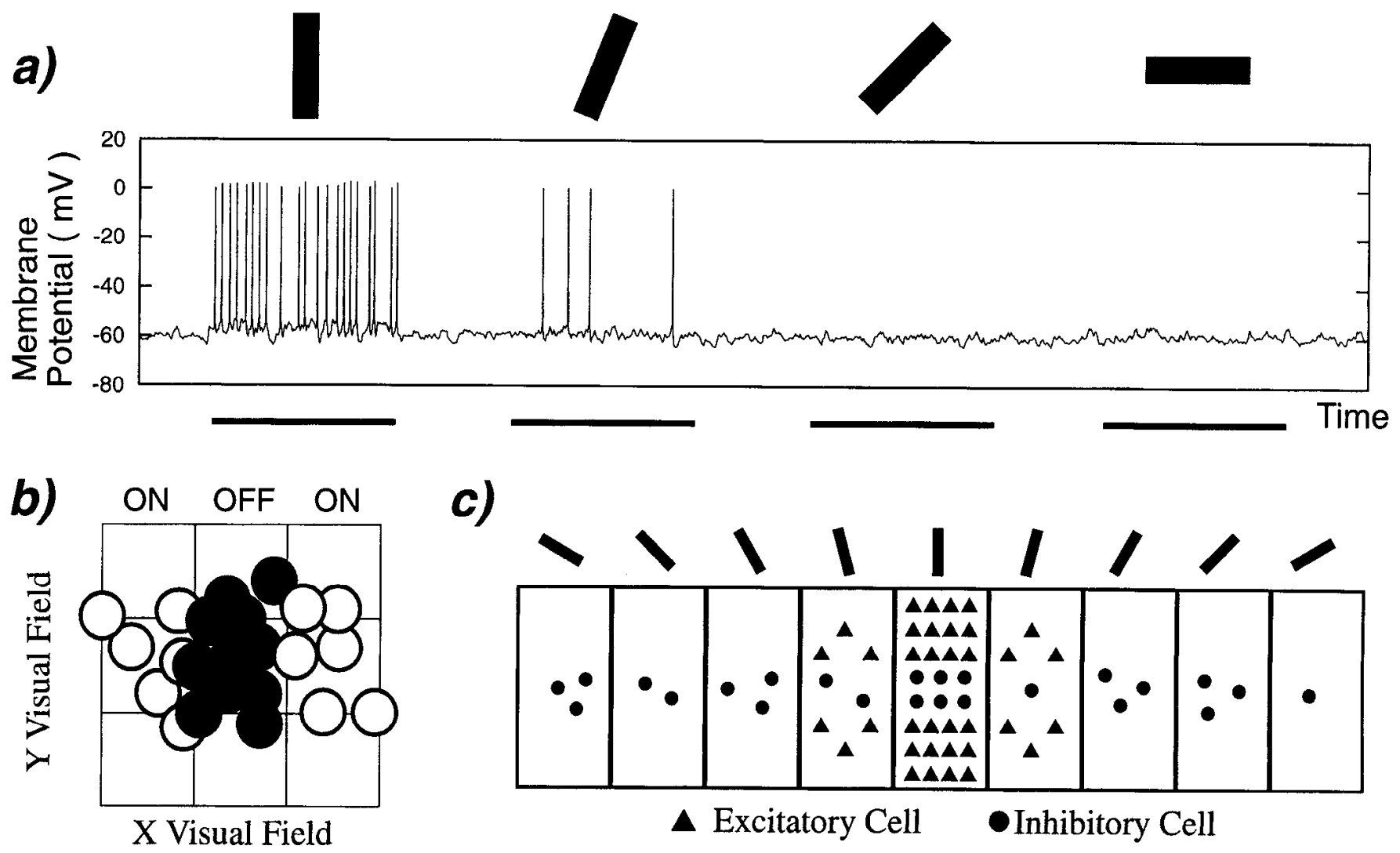

Figure 2. Response of a cell selective for $0^{\circ}$ stimuli. $a$, Simulated intracellular trace from one cell in the model network in response to flashed dark bars oriented at $0^{\circ}, 22.5^{\circ}, 45^{\circ}$, and $90^{\circ}$. Horizontal bars on time axis indicate $500 \mathrm{msec}$ stimulus presentation. $b$ and $c$, Thalamic $(b)$ and cortical $(c)$ input fields of this cell. ON (white) and OFF (black) thalamic subfields exhibited only a mild orientation bias for $0^{\circ}$ stimuli. Cortical excitatory (triangles) and inhibitory (circles) inputs arose most densely from cells within the $0^{\circ}$ column. Cortical connection probabilities fell off with distance, and no connections were permitted beyond the $60^{\circ}$ column. Inhibitory distribution was broader than the excitatory distribution.

Sharp orientation selectivity was observed across a broad range of stimulus contrasts. Mean HW tuning $(n=105)$ for $5 \%$, $15 \%$, and $100 \%$ contrast stimuli were $18.3^{\circ} \pm 0.6^{\circ} \mathrm{SD}, 17.4^{\circ} \pm$ $0.7^{\circ} \mathrm{SD}$, and $17.7^{\circ} \pm 0.6^{\circ} \mathrm{SD}$, respectively. As stimulus contrast increased from $5 \%$ to $100 \%$ average peak responses of excitato-

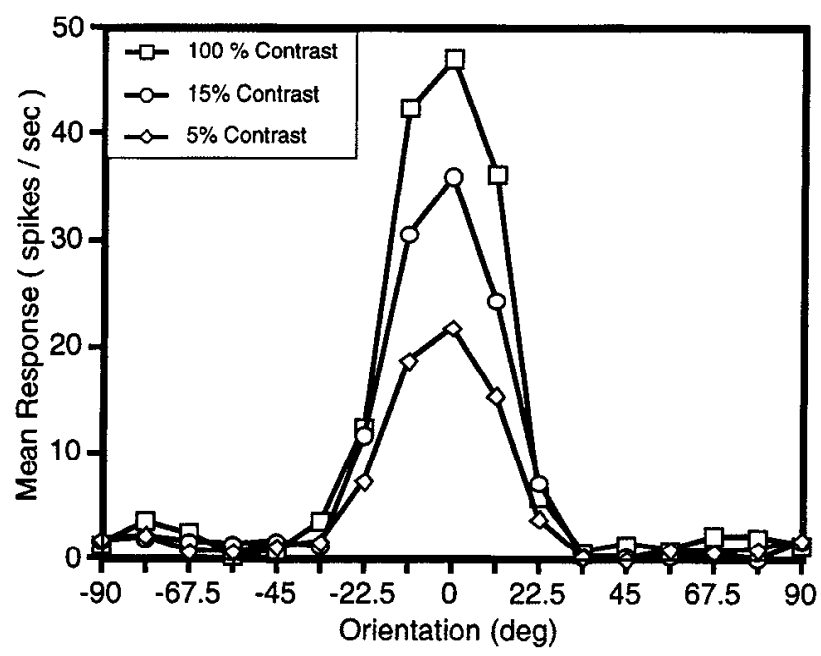

Figure 3. Sharpness of orientation selectivity remained approximately constant across stimulus contrast values. As contrast increased, peak response increased but selectivity did not broaden. ry neurons increased by $122 \%[22.1 \pm 4.8 \mathrm{sp} / \mathrm{s}( \pm \mathrm{SD})$ vs 49.1 $\pm 17.1 \mathrm{sp} / \mathrm{s}]$. This contrast invariance of orientation tuning in the model replicates experimental findings (Sclar and Freeman, 1982). Figure 3 displays orientation response curves at three different contrasts for an example cell.

The mechanisms underlying orientation tuning of the model were investigated by measuring the postsynaptic potentials (PSPs) contributed by different synaptic input sources. Both excitatory and inhibitory PSPs were strongest at the preferred orientation (see Fig. $4 a, b$ ). Notably, stimulus-evoked IPSPs (in excess of spontaneous levels) were, on average, 8.3 times as strong for the preferred orientation as for the orthogonal or cross-orientation $\left(90^{\circ}\right)$ stimulus. These PSP tuning properties of the model are consistent with intracellular reports of weak cross-orientation IPSPs and strong iso-orientation IPSPs (Ferster, 1986; Douglas et al., 1991a).

In the model, the EPSP tuning resulted from a combination of broadly tuned thalamocortical input and sharply tuned corticocortical excitation. Broad tuning of thalamocortical input resulted from the low length-to-width ratios of the (regions of thalamic convergence onto) cortical subfields (see Fig. 2c). Sharp tuning of cortical EPSPs reflected input from well-tuned cortical excitatory cells with similar orientation preferences. Cortical inhibitory inputs were also drawn most heavily from within the preferred orientation column (see Fig. $2 b$ ) and these cells were also well tuned. Cortical inhibitory inputs were drawn 

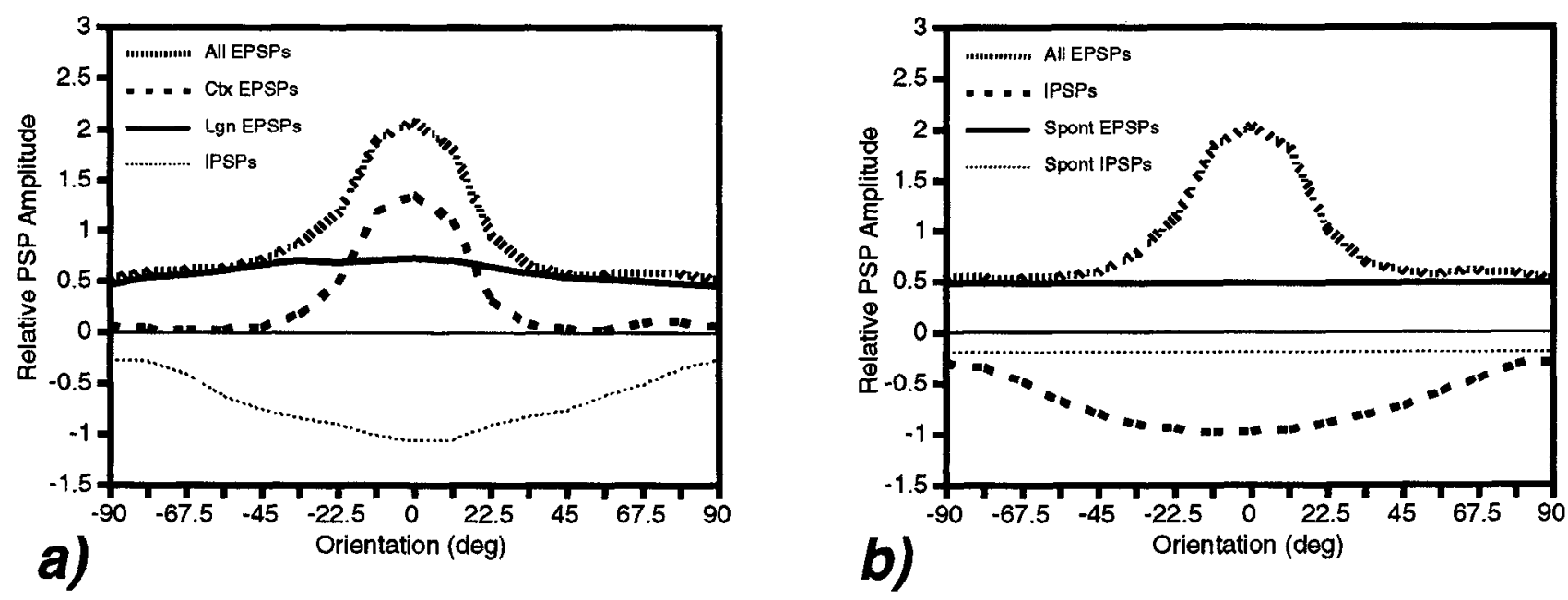

Figure 4. Orientation tuning of postsynaptic potentials. a, Postsynaptic potentials evoked in the example cell by thalamic excitatory, cortical excitatory, and cortical inhibitory synaptic inputs. LGN EPSPs were very broadly tuned. IPSPs were strongest at the preferred orientation $\left(0^{\circ}\right)$ and weakest at the cross-orientation $\left(90^{\circ}\right)$. Cortical EPSPs provided the strongest orientation-selective input. Net EPSPs were, therefore, well-tuned for $0^{\circ}$ stimuli. $b$, Averaged EPSP and IPSP inputs for all excitatory $(n=84)$ cells in the $0^{\circ}$ column. Both EPSPs and IPSPS were largest in response to stimuli of the preferred orientation. Cross-orientation stimuli evoked IPSPs that were only mildly stronger than spontaneously evoked (no stimulus) IPSPs. All PSPs were scaled by $g_{\text {lcak }} /\left(1000 C_{\mathrm{m}}\right)$.

from a broader range of orientations than cortical excitatory inputs; therefore, cortical inhibition was more broadly tuned than cortical excitation. The relative broadness of cortical inhibition to cortical excitation was observed to be a critical property for the sharp orientation tuning of the model. This issue is analyzed below in Figure 6. The distinction between cortical EPSPs and net EPSPs is also important. As thalamocortical EPSPs were quite broadly tuned, the net EPSPs and IPSPs were evoked over a similar range of orientations. Here, the EPSP and IPSP tuning curves differed primarily in their slope at oblique orientations.

The PSP records revealed that cortical excitatory inputs were the source of the largest and best-tuned orientation signal (see Fig. 4). Therefore, cortical excitation was the leading cause of sharp orientation selectivity. This finding may appear paradoxical as sharp tuning of cortical neurons was both the "effect" and the "cause" of the effect; however, in a feedback circuit such an explanation is not tautological. Rather, it implies that the effect is an emergent property of the recurrent circuitry.

Because sharp orientation selectivity resulted from cortical feedback, rapid sharpening of EPSP tuning can be observed in the model's intracellular records at the beginning of a response. Broadly tuned thalamocortical EPSPs are quickly joined by sharply tuned intracortical EPSPs. Pei et al. (1994) have recently reported a similar sharpening in PSP tuning in vivo. However, the temporal evolution of tuning is less apparent in the model's extracellular traces. For nearly all model cells, sharp orientation selectivity emerged before or just after the first spike of the response. That is, there is little or no unoriented transient component to model extracellular responses. This is consistent with experimental reports (e.g., Vogels and Orban, 1991). Due to the integrative properties of membranes, response latencies were generally shortest for preferred stimuli (cf. Dean and Tolhurst, 1986). This "head start" for preferred orientations likely contributed to the rapid emergence of sharp tuning.

Tuning contributions of feedforward and inhibitory circuit components

To further investigate the mechanisms underlying orientation selectivity in the model, the maximal synaptic conductances (strengths) for all cortical inhibitory and/or cortical excitatory synapses were manipulated (Fig. 5). The precise set of network connections, however, was otherwise unaltered. Inactivation of cortical excitatory and cortical inhibitory synapses $\left(\bar{g}_{\text {CTX:EX }}=\right.$ $\bar{g}_{\mathrm{CTX} \text { IN }}=0$ ) revealed tuning effects of the converging thalamocortical inputs. LGN inputs alone generated broad tuning with a large variance in tuning across the population of cortical neurons. Mean excitatory cell $\mathrm{HW}$ tuning was $53.3^{\circ} \pm 19.3^{\circ} \mathrm{SD}(n$ $=84$ ). Mean inhibitory cell $\mathrm{HW}$ tuning was $63.6^{\circ} \pm 20.5^{\circ} \mathrm{SD}$ $(n=21)$. Thirteen of 84 excitatory neurons were unoriented (responses to all orientations above half-maximal response), while only two neurons exhibited tuning better than $30^{\circ} \mathrm{HW}$ $\left(28.0^{\circ}, 29.8^{\circ}\right)$. The most sharply tuned neuron in the feedforward circuit was more broadly tuned than the most broadly tuned cell in the full network. This demonstrates that the role of intracontical excitation was not simply to "convey" sharp tuning from a few cells, which receive highly oricnted thalamocortical inputs, to other neurons.

Response rates were moderate in the feedforward network. Mean peak response of excitatory neurons was $25.3 \pm 1.7 \mathrm{SD}$ spikes per second $(\mathrm{sp} / \mathrm{s})$ and thus was substantially lower than the mean peak response in the full network $[49.1 \pm 7.2 \mathrm{sp} / \mathrm{s}$ $( \pm S D)]$. Manipulations that raised the firing rate of the thalamocortical (feedforward only) network without altering the relative tuning of PSPs due to LGN input, such as increasing $\bar{g}_{\mathrm{LGN}}$, consistently caused a broadening of tuning. It is well known (e.g., Creutzfeldt et al., 1974b) that the existence of the spike threshold serves to enhance the output response tuning relative to the input PSP tuning. Subtracting a fixed quantity from all orientations enhances their relative differences. This is known as the "iceberg" effect, and is strongest when the threshold lies just below the peak input value. Proportionally increasing all input values reduces the iceberg effect and yields broader tuning. Therefore, the feedforward model exhibits a tradeoff between response amplitude and selectivity.

Simulations were also performed on a variation of the model with normal intracortical inhibition, normal thalamocortical excitation, but inactivated intracortical excitation $\left(\bar{g}_{\mathrm{CTX} \text { Ех }}=0\right)$. 


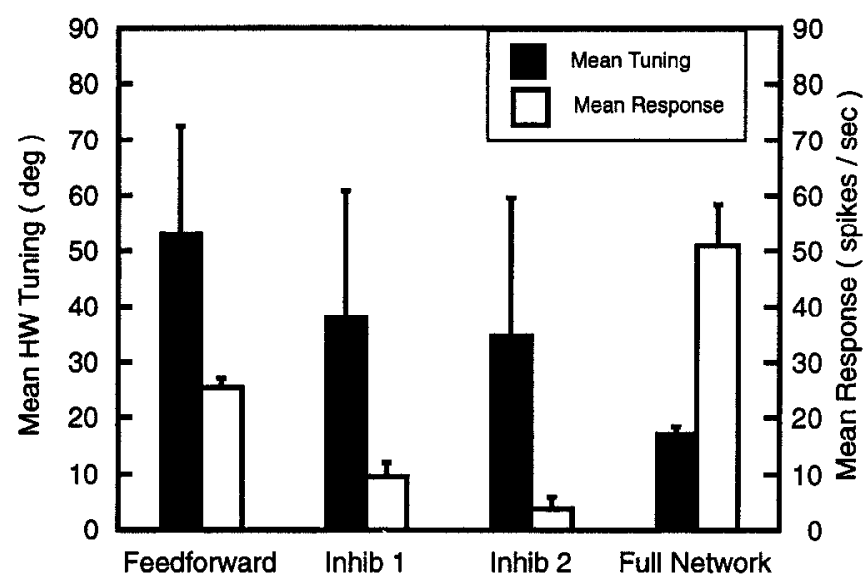

Figure 5. Recurrent network tuning properties compared to those of the network components (see Results). The thalamocortical connections of the network alone (feedforward) generated broad orientation tuning and moderate responses. Intracortical inhibitory connections enhanced orientation tuning, but did so at the cost of reduced responsiveness. Without cortical excitation the (Inhib I) network failed to achieve mean physiological values for orientation selectivity. Doubling the strength of inhibition (Inhib 2), further reduced responses but provided only a modest sharpening of orientation tuning. In contrast, the full recurrent network exhibited both physiologically sharp orientation tuning and robust responses. $n=84$ cells; error bars indicate SD.

This network ("inhib 1") exhibited tuning sharper than that of the feedforward network, but significantly broader than that of the full feedback network. Mean excitatory cell HW tuning was $38.4^{\circ} \pm 22.7^{\circ} \mathrm{SD}(n=84)$. Mean inhibitory cell $\mathrm{HW}$ tuning was $60.7^{\circ} \pm 20.3^{\circ} \mathrm{SD}(n=21)$. Only 9 of 84 excitatory cells exhibited $\mathrm{HW}$ tuning $<20^{\circ}$, while 12 excitatory neurons were classified as unoriented. This network also exhibited lower response rates than either the full network or the feedforward network. Mean peak response of excitatory neurons was $9.8 \mathrm{sp} / \mathrm{s}$ $\pm 2.3 \mathrm{sp} / \mathrm{s}$ SD. Due to broad tuning of inhibitory neurons in the "inhib 1" network, the IPSP tuning was nearly flat across orientations with a mild bias for the preferred orientation. The tuning advantage that this inhibitory network enjoys over the feedforward network therefore can be attributed to an "iceberg" effect, providing "flat," hyperpolarizing inhibition is equivalent to raising the spike threshold.

To further investigate iceberg-type effects in this model, the maximal inhibitory synaptic conductances were doubled $\left(\bar{g}_{\mathrm{CrX} \cdot \mathrm{IN}}\right.$ $=10 \mathrm{nS})$ and cortical excitation remained off $\left(\bar{g}_{\mathrm{CTX} \cdot \mathrm{Ex}}=0 \mathrm{nS}\right)$. This ("inhib 2") network exhibited only a mild improvement in orientation tuning over the "inhib 1 " network. Mean excitatory cell HW tuning was $35.2^{\circ} \pm 24.2^{\circ} \mathrm{SD}$. Mean inhibitory cell HW tuning was $57.5^{\circ} \pm 20.7^{\circ} \mathrm{SD}$. The increase in inhibition preferentially enhanced the tuning of cells that received more strongly oriented thalamocortical input. Cells receiving unoriented thalamocortical input remained unoriented. The HW tuning of $25 \%(21 / 84)$ of excitatory neurons and none of the inhibitory neurons was less than $20^{\circ}$, while the tuning of $14 \%(12 / 84)$ of excitatory and $24 \%(5 / 21)$ of inhibitory neurons was classified as unoriented. The increase in inhibition also resulted in a further reduction of response rates. The mean peak response of cortical excitatory neurons was $4.0 \mathrm{sp} / \mathrm{s} \pm 2.0 \mathrm{sp} / \mathrm{s} \mathrm{SD}$.

The results of these network simulations are summarized in Figure 5. Thalamocortical inputs alone yielded broad tuning with a large variance in tuning. Addition of intracortical inhihition enhanced tuning, but did so at the cost of substantially reducing responsiveness. The spatial pattern of inhibition used in the model enhanced thalamocortical orientation biases, but could not, de novo, create orientation tuning. This inhibition mildly increased the variance in orientation tuning across cells. The full network (with corticocortical excitation) overcame the limitations of the feedforward and inhibitory networks. All neurons, even those with unoriented patterns of thalamocortical input, exhibited sharp orientation tuning. Unlike in the inhibitory networks, this tuning enhancement was accompanied by amplification of the peak response. Strikingly, the strong inhibitory ("inhib 2") network exhibited a peak response only $8.1 \%$ as strong as that of the full network, yet generated HW tuning that was still twice as broad as the full network. These results demonstrate that the orientation tuning properties of the model cannot be accounted for by either the thalamocortical or intracortical inhibitory connections it utilized. Thus, these results demonstrate the utility of local, recurrent, cortical excitatory connections in the generation of sharp orientation selectivity by the model.

\section{Analysis of orientation tuning requirements}

To further illuminate the mechanism by which this model achieved sharp orientation tuning and robust responses (despite utilizing poorly oriented thalamocortical inputs and iso-orientation inhibition), additional analysis was performed. Figure $6 a$ displays the mean orientation response curve for cells in the thalamocortical network and an example of a "desired" orientation response curve with $\mathrm{HW}$ tuning of $20^{\circ}$ (typical tuning for simple cells; Orban, 1984). The desired tuning curve was scaled so that the peak responses of the two curves were equal. For cells to achieve $20^{\circ} \mathrm{HW}$ tuning, the difference between the desired orientation tuning response and the thalamocortical response must be provided by cortical inputs. Therefore, the difference curve (see Fig. $6 a$ ) reveals the shape of orientation tuning of the net cortical contribution required to achieve sharp orientation selectivity. This curve indicates that net cortical inhibition should be strongest at approximately $20-40^{\circ}$ from the preferred orientation. Mild net cortical inhibition is required at the cross-orientation. Since the desired response is roughly zero at the cross-orientation, increased levels of cross-orientation cortical inhibition are also consistent with these curves; however, additional cross-orientation inhibition is not required to achieve physiological tuning values.

The net cortical tuning curve indicates that little or no isoorientation inhibition is required; an iso-orientation-specific increase in inhibition would both reduce responsiveness and broaden tuning. Since experimental intracellular recordings indicate that cortical inhibition is actually strongest at the isoorientation (Ferster, 1986; Douglas et al., 1991a; but see Pei et al., 1994), the net cortical orientation tuning curve cannot be accounted for solely by the cortical inhibitory inputs. However, the net cortical curve can be matched by combination of relatively broad iso-orientation cortical inhibition and relatively narrow iso-orientation cortical excitation. Such a "center-surround" structure is functionally similar to difference of gaussian (DOG) operators that are commonly used in computer vision models (e.g., Marr and Hildreth, 1980; Grossberg, 1983; Grossberg and Mingolla, 1987). Figure $6 b$ displays the average cortical excitatory and inhibitory inputs (PSPs) to excitatory cortical cells ( $n$ $=84$ ) in the full model. The net cortical orientation tuning curve produced by their sum exhibits the same center-surround structure displayed in the difference curve of Figure $6 a$. These curves differ primarily in the presence of net cortical iso-orientation 
excitation within the model. This excitation was reflected in the higher peak response rates of the full network as compared to the thalamocortical network.

This analysis demonstrates that narrowly tuned cortical excitation can provide the "missing link" between the combination of broadly tuned thalamocortical excitatory inputs and iso-orientation inhibitory inputs on the one hand, and sharply tuned orientation output responses on the other hand. The "centersurround" orientation tuning mechanism described here can be generated by any of a family of pairs of excitatory and inhibitory cortical inputs in which excitation and inhibition are approximately balanced and inhibition is more broadly tuned than excitation. Such a family of balanced excitatory and inhibitory cortical inputs was generated in the model as stimulus contrast was varied (not shown). In addition, simulations of networks with spatial connectivity distributions that differed by $20 \%$ or less from the values of either $\sigma_{\mathrm{EXCIT}}$ or $\sigma_{\text {INHIB }}$ than that used in this model also exhibited the necessary balanced, "center-surround" structure, and produced emergent, sharp orientation selectivity. The critical property was the orientation bandwidth of the net cortical center-surround structure (see Fig. 6). Cortical amplification could occur within approximately $20^{\circ}$ of the preferred orientation, but net cortical inhibition was required at more oblique orientations. As cortical excitatory inputs were more broadly distributed, cortical inhibition needed to be stronger. Sharper thalamocortical orientation bias eased the restrictions on center-surround structures; however, net excitation in the surround disrupted even very sharp thalamocortical tuning.

To further explore the robustness of the model, orientation behavior was explored for a broad range of cortical excitatory and inhibitory synaptic strengths. Mean response and orientation tuning of the summed responses of all excitatory neurons $(n=$ 84 ) in the $0^{\circ}$ column were measured for each parameter set (see Fig. 7). Several trends were apparent. Most importantly, there was a robust region of "balanced" excitatory and inhibitory strengths for which sharp tuning and vigorous responses were observed. Not surprisingly, increasing inhibitory strengths had the effect of decreasing responses, while increasing excitatory strengths produced higher responses. Increasing inhibition also generally sharpened tuning. In contrast, increasing excitation had a consistent, biphasic effect on orientation tuning. At low cortical excitation levels, increasing excitation sharpened tuning, while at higher levels further increases broadened tuning. This effect is most apparent in the inhibition $=5 \mathrm{nS}$ column of Figure 7. The turning point for this biphasic effect increased as inhibitory strength increased. This relationship was reflected in the diagonal band of "balanced" excitatory and inhibitory strengths that yield both sharp tuning and robust responses. In the region below this diagonal inhibition dominated, causing reduction of response. In the region above the diagonal band excitation dominated, causing nonselective amplification of all responses and thus a broadening of tuning. Explorations of networks with different spatial spreads of cortical connections also revealed similar (but shifted) diagonal bands of "balanced" excitation and inhibition for which sharp tuning was observed.

It is also important to report on the form of the inhibition utilized in the model, since experimental evidence suggests that shunting or divisive inhibition can contribute only modestly to oricntation tuning (Douglas ct al., 1988; Berman et al., 1991; Dehay et al., 1991; Ferster and Jagadeesh, 1992). By construction, the model utilized only hyperpolarizing inhibition and not shunting inhibition. The current contributed by excitatory syn-
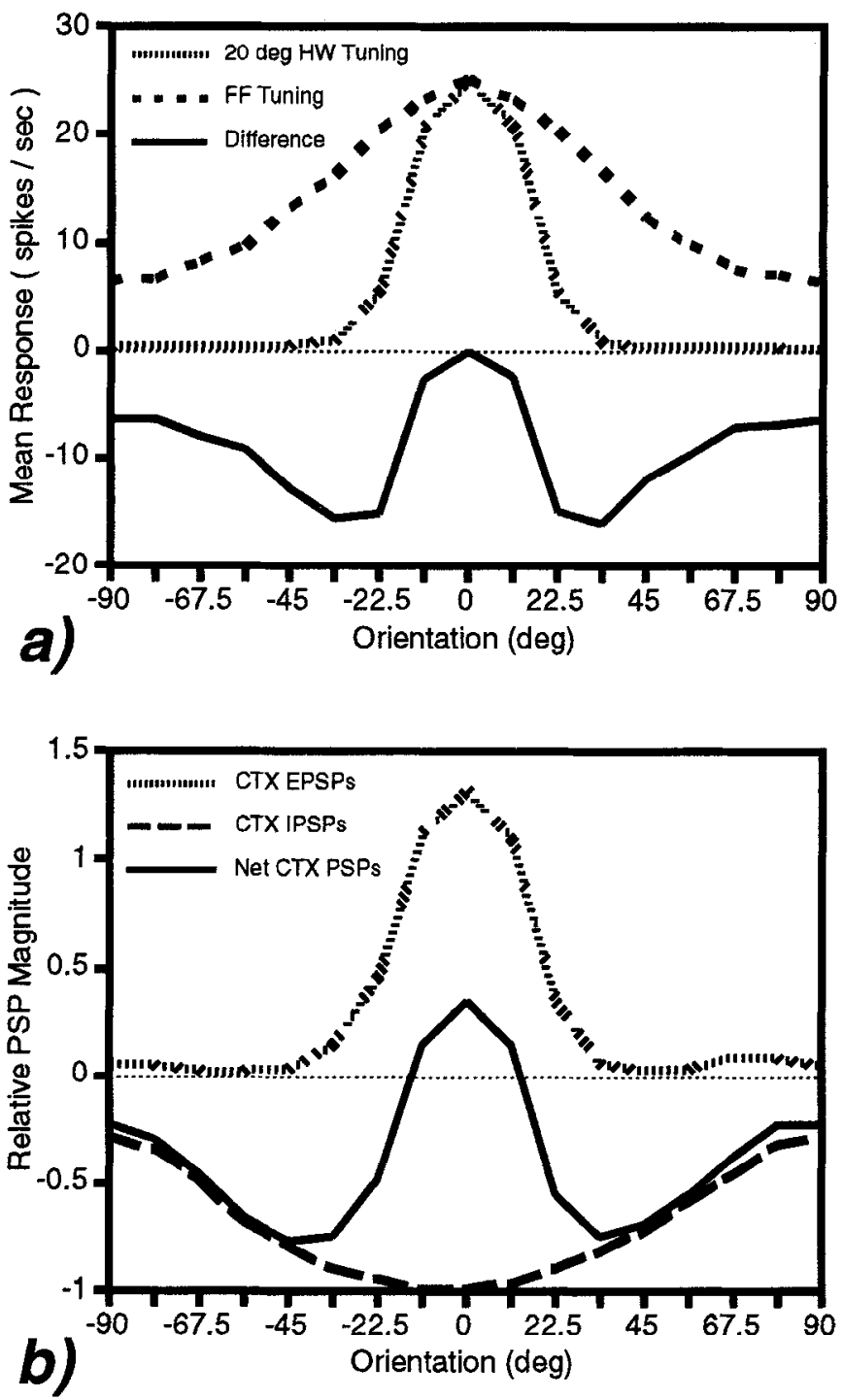

Figure 6. Cortical requirements for sharp orientation selectivity. $a$, Comparison of orientation responses produced by thalamocortical inputs alone (FF Tuning) with typical physiological tuning ( $20 \mathrm{deg} \mathrm{HW}$ Tuning). The difference between these curves must be contributed by intracortical inputs. Note that net inhibition is most strongly required approximately $20-40^{\circ}$ from the preferred orientation. $b$, Average cortical PSPs received by excitatory cells in the $0^{\circ}$ column. Narrow iso-orientation excitation and broader iso-orientation inhibition combined to yield "center-surround" cortical orientation tuning with net excitation in response to preferred stimulus orientations and net inhibition for nonpreferred stimuli. Net cortical tuning satisfied inhibitory requirements of the difference curve (in $a$ ) and amplified preferred responses. PSPs scaled as in Figure 4.

apses was independent of synaptic inhibitory conductances, per se. In the model, $\mathrm{Cl}^{-}$-mediated inhibition has a hyperpolarizing effect due to the driving force produced when a postsynaptic neuron is depolarized to near threshold $(-55 \mathrm{mV})$. A more biophysically detailed implementation in which modest shunting was permitted would have reduced the amount of inhibition required to achieve sharp tuning (Bush and Sejnowski, 1994); however, shunting was not required. For the sake of thoroughness, we report that cross-orientation stimuli increased the average inhibitory conductance from a rest value of $5.4 \mathrm{nS}$ (due to spontaneous firing of inhibitory neurons) to $11.5 \mathrm{nS}$. The average net (leak plus synaptic) conductance increased by $20.5 \%$ 

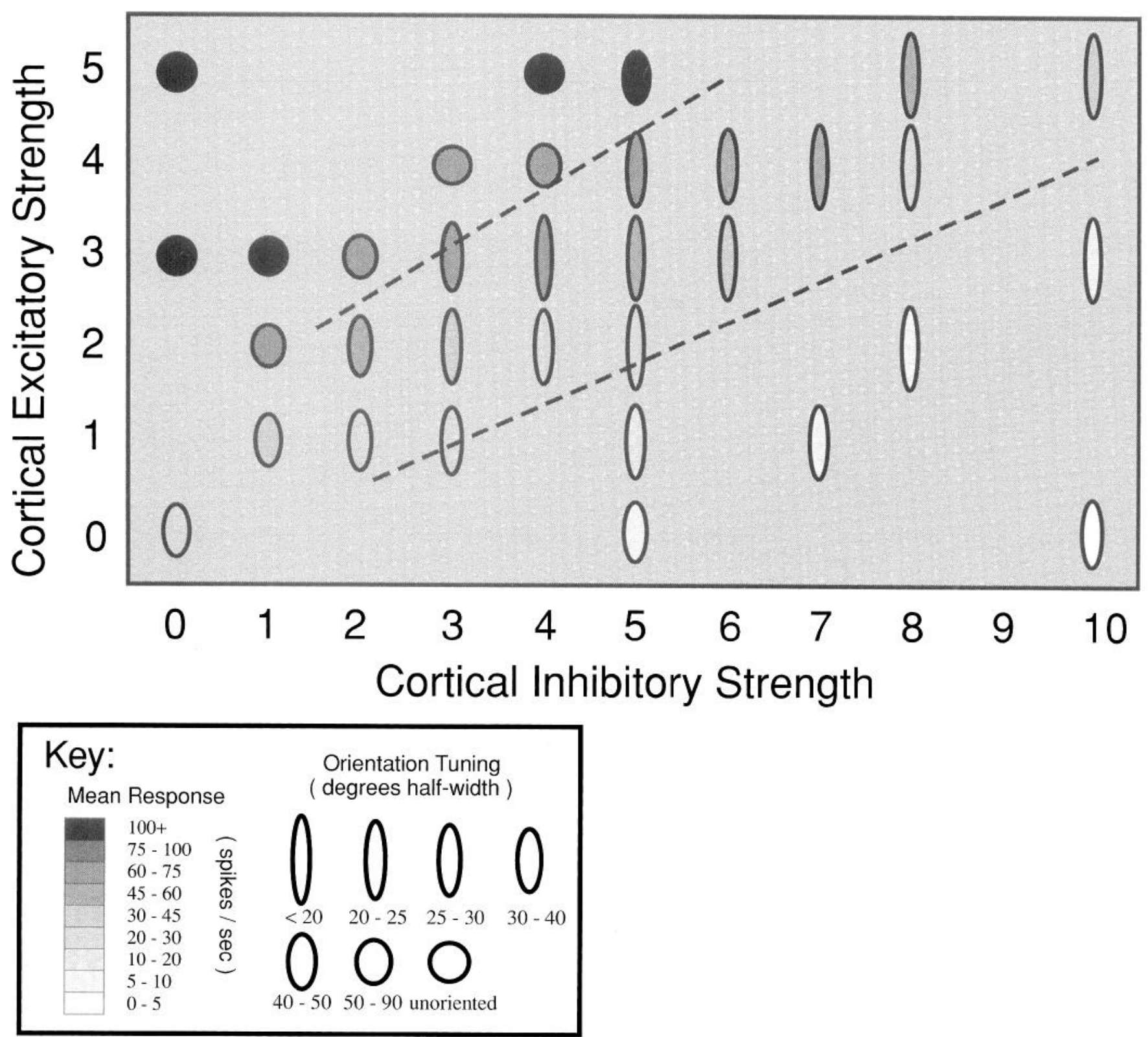

Figure 7. Sensitivity of the model to cortical excitatory and inhibitory strengths: average peak response (indicated by symbol shading) and orientation tuning bandwidth (indicated by symbol shape) of averaged responses of cortical excitatory neurons $(n=84)$ in $0^{\circ}$ column, for different cortical synaptic strengths $\left(\bar{g}_{\text {CTX.EX }}, \bar{g}_{\text {CTX.IN }}\right.$ in nS). The model exhibited sharp orientation tuning and strong responses provided that cortical excitation and inhibition were approximately balanced. The region between the two dashed lines defines the region of parameter space that satisfied this "balance" requirement. Where inhibition dominated, response rates fell; where excitation dominated, tuning broadened. Note that increasing excitatory strength had biphasic effects. At low excitation levels, increasing excitation amplified preferred responses and thus sharpened tuning. At high excitation levels, increasing excitation amplified all responses and therefore broadened tuning.

from $33.6 \mathrm{nS}$ to $40.5 \mathrm{nS}$. Experimental reports suggest net conductance changes of $20 \%$ or less (Douglas et al., 1988; Berman et al., 1991; Ferster and Jagadeesh, 1992). As model neurons were comprised of only a single compartment, the average net conductance value measured here likely overestimated the conductance change that would be recorded at the soma of a real neuron. Synaptically evoked conductance changes measured at the soma decrease with synaptic distance from the soma (Koch et al., 1990).

The model also made use of fast, feedforward inhibition; however, this property was not critical to generation of sharp orientation tuning. Elimination of the relative timing difference be- tween thalamocortical inputs produced tuning that was as sharp (in some cases sharper) than the results presented above. However, fast feedforward inhibition reduced the net inhibitory responses by $50 \%$ or more. Elimination of timing differences led to higher recurrent excitatory amplitudes. Feedback inhibition compensated to produce sharp tuning, but net inhibitory amplitudes increased to match excitatory amplitudes. All orientations were effected, so the orientation tuning width of inhibition was similar for both forms of inhibition. Elimination of timing differences also had an effect on the temporal emergence of tuning; with slower inhibition a higher percentage of cells gave off a "transient" response spike before settling into their tuned re- 
sponses. But these transient periods were modest compared to the 50-100 msec transient periods observed during simulations (data not shown) in which feedforward inhibition was completely eliminated (no thalamocortical excitation of inhibitory cells). Thus, in the model, rapid feedforward inhibition contributed to the fast emergence of sharp orientation selectivity

\section{Pharmacological blockade studies}

Pharmacological blockade studies provide additional methods of revealing neural circuitry properties. Three such pharmacological blockades were addressed in simulations: silencing of $\mathrm{ON}$ center retinal and thalamic cells by injection of APB in retina; reduction of intracortical inhibition across a small, localized population of neurons by iontophoresis of bicuculline; and intracellular blockade of inhibition in single cortical neurons.

Experiments in cat and monkey have demonstrated that injection of the glutamate agonist 2-amino-4-phosphonobutyrate (APB) into the retina reversibly silences activity of ON-center retinal bipolar, retinal ganglion, and lateral geniculate cells, but has no effect on the center surround antagonism of OFF-center cells (Schiller, 1982; Horton and Sherk, 1984). Similarly the ON subfields of cortical simple cells disappear, while the OFF subfields persist. Under these conditions orientation selectivity remains sharp; however, response rates fall dramatically (Schiller, 1982; Sherk and Horton, 1984). These experiments effectively invalidate orientation selectivity models that rely on strong interactions between ON and OFF subfield types (e.g., Heggelund, 1981).

APB injection experiments were simulated by silencing ONcenter retinal and thalamic cells, while leaving OFF-center responses unchanged. Model cortical cells retained their sharp orientation tuning. Mean excitatory cell $\mathrm{HW}$ tuning was $14.5^{\circ} \pm$ $1.3^{\circ} \mathrm{SD}$. Mean inhibitory cell HW tuning was $17.7^{\circ} \pm 0.8^{\circ} \mathrm{SD}$ (see Fig. 8). In further agreement with experiment, response rates dropped dramatically. Mean peak response rate of excitatory cells dropped by $67.6 \%$ to $15.9 \mathrm{sp} / \mathrm{s}$. The reduction in response rates was caused by the silencing of LGN ON cells. Thalamocortical input was reduced at all orientations. Mean thalamocortical input dropped by $40.2 \%$ at the preferred orientation and by $37.7 \%$ at the cross-orientation. The withdrawal of ON excitation had a mild iceberg effect and accounted for the slight tuning enhancement observed. Thus, in the model, interactions between ON and OFF subfields were not critical to the generation of sharp orientation selectivity. In a prior version of the model (Somers et al., 1995), in which separate ON- and OFF-center inputs were not explicitly modeled, a similar cortical architecture also yielded sharp tuning. This further supports the idea that interactions between $\mathrm{ON}$ and OFF channels are not necessary for the generation of orientation selectivity.

The most direct paradox in the experimental literature on orientation selectivity lies in the dramatic effects observed under different forms of intracortical inhibitory blockade. Extracellular iontophoretic application of the $\mathrm{GABA}_{\mathrm{A}}$ antagonist bicuculline methiodide reduced inhibitory synaptic transmission across a local population of cells and disrupted orientation tuning. Sufficiently large bicuculline doses abolished orientation selectivity. Bicuculline application also substantially increased response rates. These results argue for a critical role for intracortical inhibition in orientation selectivity (e.g., Sillito et al., 1980). In contrast, our laboratory recently reported that intracellular blockade of inhibition had negligible effect on orientation tuning. In these experiments whole-cell pipettes were used to deliver CsF-

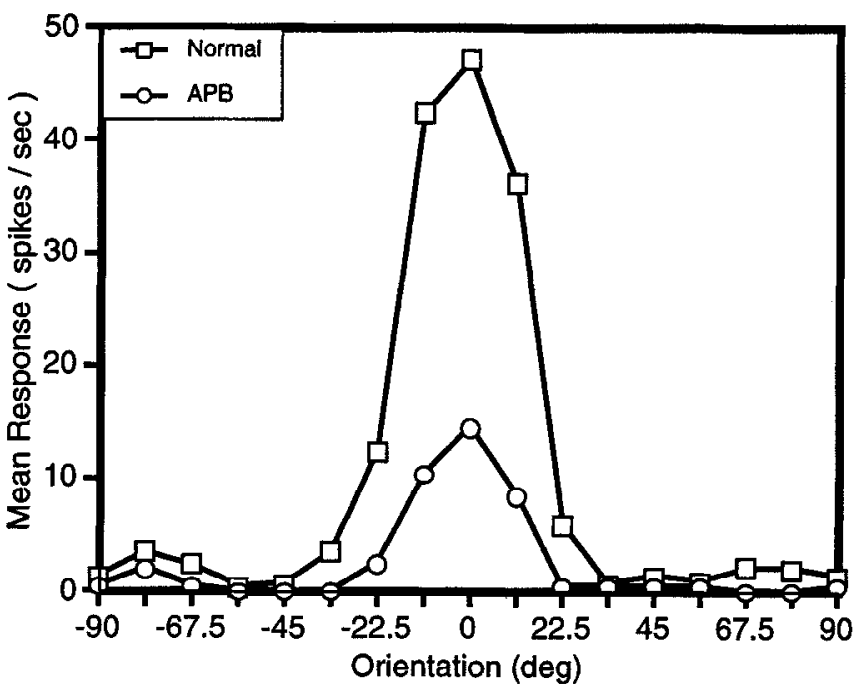

Figure 8. Cortical response under APB blockade of ON channel inputs (shown for same cell as earlier figures). Orientation tuning remained sharp and the peak response fell dramatically. This indicates that sharp orientation tuning did not rely on interactions between $\mathrm{ON}$ and OFF subtields.

DIDS solution intracellularly to silence inhibitory voltage conductances $\left(\mathrm{Cl}^{-}, \mathrm{K}^{\prime}\right)$. A mild, fixed hyperpolarizing current was injected to compensate for the increase in spontaneous firing rate. The critical difference between the two sets of inhibitory blockade experiments appears to be the number of cells that lost inhibitory inputs. Disruption of orientation selectivity requires long bicuculline ejection times (Sillito et al., 1980; Nelson, 1991). This suggests that the drug effects spread across a local population of neurons. In contrast, intracellular blockade affects only the recorded neuron. This issue was explored in the model. Bicuculline application was simulated by a $50 \%$ reduction in $\bar{g}_{\text {CTX.IN }}$ for all neurons $(n=105)$ in the $0^{\circ}$ column; synaptic connections onto neurons in other columns were unaffected. CsF-DIDS application was simulated by a $100 \%$ reduction in $\bar{g}_{\mathrm{CTX} \text {.N }}\left(\mathrm{Cl}^{-}\right.$channels $)$and an $80 \%$ reduction in $\bar{g}_{\mathrm{AHP}}\left(\mathrm{K}^{+}\right.$channels) in a single neuron. The DIDS cell was either injected with a fixed (for all orientations) $-0.3 \mathrm{nA}$ hyperpolarizing current or received no injected current.

A simulated bicuculline intracellular response trace (for the same cell shown in Fig. $2 a$ ) is shown in Figure $9 a$. Under bicuculline application, all cells in the $0^{\circ}$ column $(n=105)$ became unoriented and peak excitatory responses increased by $87.4 \%$ to $92.0 \pm 6.9 \mathrm{sp} / \mathrm{s}$. Both effects are consistent with experimental reports (Sillito et al., 1980; Nelson, 1991). With inhibitory efficacy reduced, the columnar population amplified responses to all stimuli and thus disrupted tuning. Cellular effects also contributed modestly to tuning loss; high input levels (produced by network amplification) drive cell responses to levels at which they are less sensitive to input differences. Bicuculline firing rates were higher than the normal firing rates, but they were far below full saturation levels (maximum firing rate $>$ $300 \mathrm{sp} / \mathrm{s}$ ). In agreement with experiment (Sillito et al., 1980; Nelson, 1991), response rates and tuning disruption effects varied with bicuculline dosage. These simulations restricted bicuculline effects to a single cortical column. In vitro, wider spatial spreads of bicuculline, which occur even at low dosage, permit excitatory activity to propagate across columns (Chagnac-Amitai 

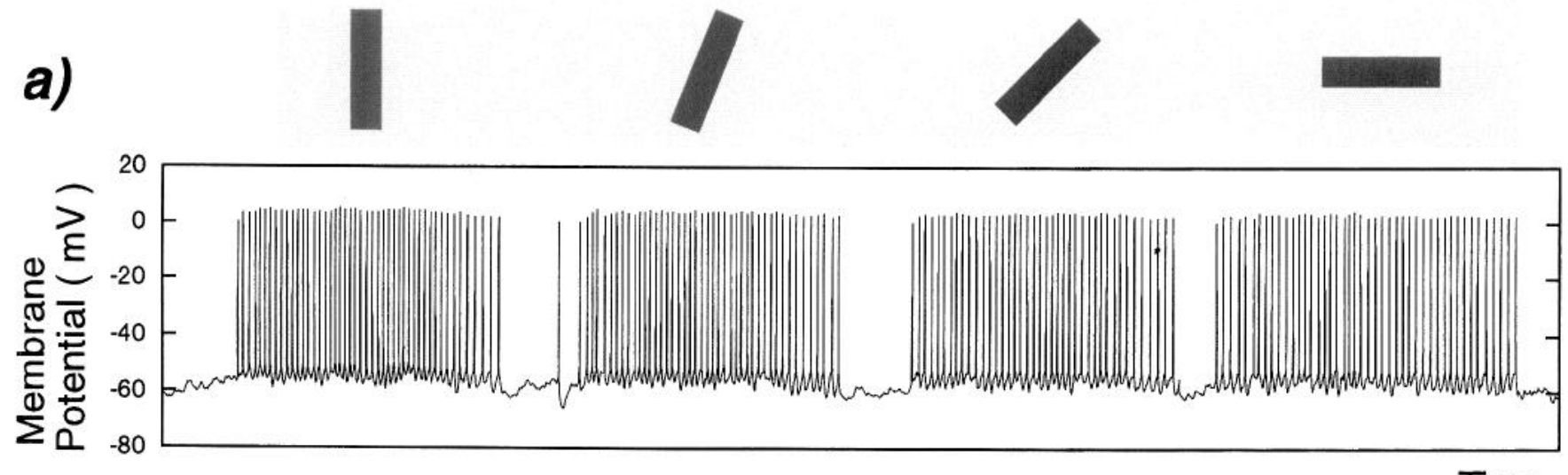

b)
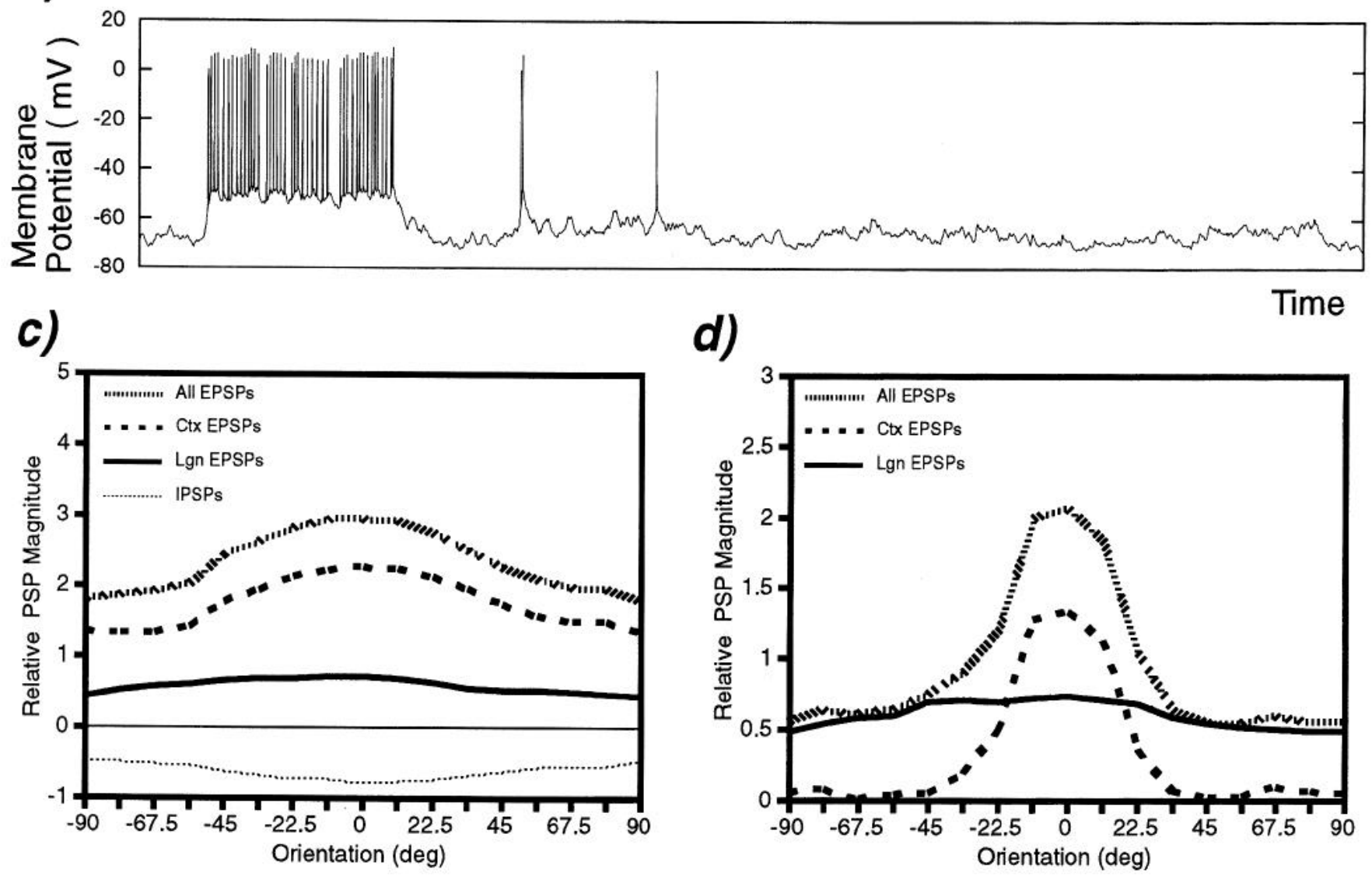

Figure 9. Cortical response under two forms of intracortical inhibitory blockade: $a$, simulated intracellular trace (same cell shown in Fig. $2 a$ ), with bicuculline application, and $b$, with CsF-DIDS application (with $-0.3 \mathrm{nA}$ current injected; $b$ ) in response to flashed bars oriented at $0^{\circ}, 22.5^{\circ}$, $45^{\circ}$, and $90^{\circ}$. Orientation tuning was disrupted only for the bicuculline case. The critical difference between the two forms of inhibitory blockade was the effect on the tuning of cortical EPSPs. $c$, Reduction of inhibition across the column resulted in a loss of cortical EPSP tuning. Thus, bicuculline disrupted both net EPSP tuning and response tuning. Strong inhibition was evoked with the reduction in inhibitory synaptic strength due to cortical excitation of inhibitory neurons; however, this inhibition was insufficient to rebalance cortical excitation. Note that cross-orientation IPSP levels exceeded that of the normal case (see Fig. 4a). In contrast, silencing of inhibition in a single cell $(d)$ had negligible effect on the tuning of other cells. Therefore, cortical EPSPs and net EPSPs retained their orientation selectivity under CsF-DIDS. PSPs scaled as in Figure 4.

and Connors, 1989). Propagation of excitation across orientation columns would further disrupt tuning.

Figure $9 b$ shows an intracellular trace from the same cell under simulated DIDS application. This cell retains its sharp orientation tuning. DIDS simulations were performed individually for 10 neurons (all excitatory) both with and without injected current. With injected current the 10 cells exhibited mean HW tuning of $17.4^{\circ} \pm 0.9^{\circ} \mathrm{SD}$. In the normal network these cells exhibited mean HW tuning of $17.2^{\circ} \pm 0.7^{\circ}$ SD. Under DIDS application and without current injection these 10 cells exhibited mean HW tuning of $25.4^{\circ} \pm 1.7^{\circ} \mathrm{SD}$. Thus, the simulations, like experiment, indicate little loss of orientation selectivity with blockade of direct inhibitory inputs.

In the model, DIDS cells were sharply orientation selective 
because they received sharply tuned cortical excitatory input. The iceberg effect due to the hyperpolarizing current contributed only mildly to the DIDS tuning. The hyperpolarizing current injected was $-0.3 \mathrm{nA}$ which is only $31 \%$ as strong as the net hyperpolarizing current (synaptic plus afterhyperpolarizing) evoked by the preferred stimulus in the normal network. Current injection provided a mild iceberg effect relative to the nocurrent DIDS case, but DIDS cells with injected current exhibited $87 \%$ higher peak response on average than they did in the normal network. The high response reflects the relative weakness of the injected hyperpolarizing current as compared to the normal, stimulus-evoked hyperpolarization. Limitations of the cortical cellular model may also be responsible. It is likely that during actual experiments increased spike durations limit peak firing rates. In our simulations, spike durations were not changed.

In the model the fundamental difference between the two inhibitory blockade paradigms was the tuning of the intracortical excitatory inputs (see Fig. $9 c, d$ ). Blockade of inhibition in a single cell had a negligiblc cffect on the tuning of other cells in the network. Therefore, the cortical excitatory inputs to the blocked cell retained their sharp orientation tuning and the net input was well tuned (see Fig. 9d). Even in the absence of injected current, DIDS cells exhibited sharp tuning. In contrast, the reduction in inhibition across the local population that occurs with bicuculline dramatically altered the tuning of intracortical excitatory inputs. With insufficient "balancing" inhibition, the recurrent orientation tuning mechanism failed to "emerge" and instead became disruptive. The columnar population amplified responses to all orientations and cortical excitatory cells lost their sharp tuning (see Fig. 9c). Thalamocortical inputs were unchanged, so net EPSP tuning broadened substantially with only a residual orientation bias. Interestingly, strong IPSPs were evoked in bicuculline simulations. Bicuculline condition crossorientation IPSPs were, on average, 35\% stronger than normal cross-orientation IPSPs; however, the resulting IPSPs were insufficient to adequately balance the strong, broadly tuned EPSPs.

The inhibitory blockade simulation results are summarized in Figure 10. DIDS blockade of inhibition in single cells yielded a slight broadening of orientation tuning. Even with no inhibition and no injected current, the orientation tuning of these cells was much closer to their normal tuning than to their thalamocortical tuning. Injection of a moderate hyperpolarizing current fully restored the tuning of DIDS cells without substantially attenuating their peak responses. The sharp tuning of DIDS cells resulted primarily from the sharp tuning of their intracortical excitatory inputs. In contrast, simulated extracellular bicuculline blockade abolished orientation tuning. With insufficient balancing inhibition, intracortical excitation disrupted tuning by nonselective (but nonsaturating) amplification of responses. Note that bicuculline tuning was substantially worse than the thalamocortical tuning. In comparison, inhibitory models predict that bicuculline tuning should be no worse than the thalamocortical tuning. Thus, consideration of intracortical excitation not only provides a mechanism for the persistence of tuning under direct inhibitory blockade of single cells, but also provides a more complete explanation than do inhibitory models for the abolition of tuning under extracellular inhibitory blockade.

\section{Discussion}

Despite over 30 years of experimental and theoretical work, no single model of visual cortical orientation selectivity has been

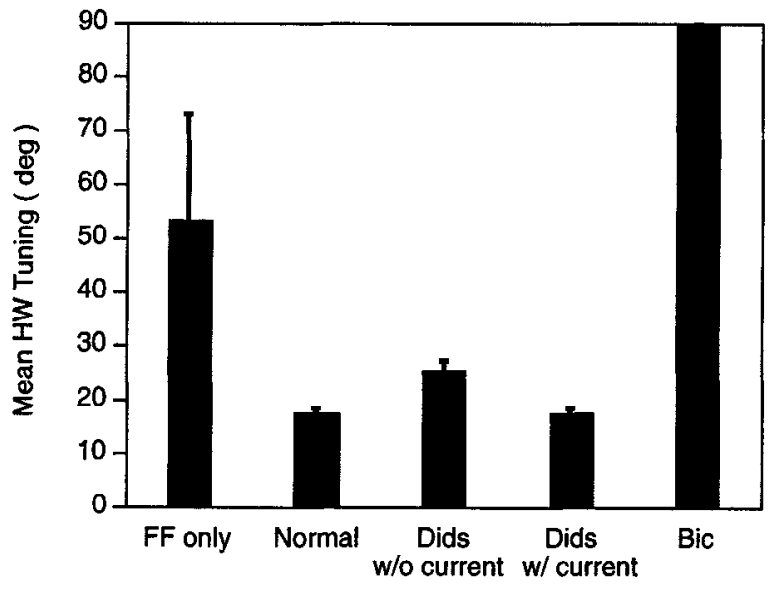

Figure 10. Summary of inhibitory blockade effects: mean orientation selectivity of excitatory neurons in the cortical column (error bars indicate SD for population). CsF-DIDS blockade of inhibition in single cells $(n=10)$ without injected current produced only a mild broadening of orientation selectivity as compared to the normal response $(n=84)$. Injection of a $-0.3 \mathrm{nA}$ hyperpolarizing current returned CsF-DIDS tuning $(n=10)$ to normal levels. Bicuculline reduction of inhibition over the $\left(0^{\circ}\right)$ columnar population caused all cells $(n=84)$ to lose orientation selectivity. Note that bicuculline tuning was worse than thalamocortical (FF) tuning alone $(n=84)$.

able to account for even the majority of experimental data. Here we have presented a model with modest assumptions which accounts for the results of most intracellular, extracellular, and pharmacological studies of orientation selectivity. Sharp orientation selectivity was achieved in all neurons without requiring that any neuron receive well-tuned thalamocortical inputs. The model relied neither on interactions between ON and OFF subfields nor on strong inhibition from nonpreferred orientations. Shunting inhibition was not required, inhibitory conductances were modest, and inhibitory neurons exhibited the same tuning properties as their neighboring excitatory neurons. Direct inhibitory inputs contributed only modestly to the tuning of any single neuron, but inhibition was critical at a population level. This apparent paradox was resolved in the model by utilizing local cortical excitation to provide strong, orientation-selective input. Since the tuning of cortical excitatory neurons was both the "effecl" and the "cause" of the effect, sharp orientation selectivity was seen as an emergent property of the recurrent cortical circuit. The orientation selectivity exhibited by this circuit also was shown to be insensitive to stimulus contrast.

\section{Key assumptions of the model}

Although the model incorporated significant biological detail, only three assumptions were critical to this model. First, converging LGN inputs must provide some orientation bias at the columnar population level. Consistent with experiment (Creutzfeldt et al., 1974a; Watkins and Berkley, 1974; Jones and Palmer, 1987; Chapman et al., 1991; Pei et al., 1994), this bias may be weak and distributed across a population with many cells that receive unoriented input. The second assumption of the model, that local $(<1 \mathrm{~mm}$ horizontal distance) intracortical inhibitory connections must arise from cells with a broader distribution of orientation preferences than do intracortical excitatory connections, differs from prior inhibitory models in that it is consistent with experimental evidence for strong iso-orientation inhibition (Ferster, 1986; Douglas et al., 1991a). Narrowly tuned iso-ori- 
entation excitation and more broadly tuned iso-orientation inhibition can be realized by a simple difference-of-gaussians-like structure in the orientation domain. This idea is supported by cross-correlation data (Michalski et al., 1983; Hata et al., 1988) and is consistent with a key hypothesis of many models of the development of orientation selectivity (e.g., Rojer and Schwartz, 1990; Miller, 1992, 1994; Swindale, 1992; Grossberg and Olson, 1994). The final assumption is that cortical inhibition must approximately balance cortical excitation. Too much inhibition produced low response rates, and too little inhibition permitted nonselective amplification of all stimulus responses. However, many sets of parameters satisfied the "balance" requirement. This hypothesis is consistent with reports that EPSP and IPSP strengths roughly covary across orientations (Ferster, 1986; Douglas et al., 1991a; but see Pei et al., 1994, for a differing view). Balanced cortical excitation and inhibition has also been invoked recently by computational models of cortical response variability (Softky and Koch, 1993; Shadlen and Newsome, 1994; Tsodyks et al., 1994; Usher et al., 1994; Bell et al., 1995).

Model cells in a column displayed a tighter distribution of orientation tuning widths than has typically been observed experimentally (e.g., Orban, 1984). Due to computational constraints many synapses were lumped together in the model, producing artificially high connection probabilities between excitatory neurons in a column. The relative uniformity of responses results from these high connection probabilities; the average path length of recurrent feedback loops is quite short and short loops lead to "consensus" responses. In networks with lower connection densities, greater diversity is exhibited. Despite the population uniformity, significant trial to trial response variability was observed.

Other parameter choices deserve mention. The efficacy of the model was demonstrated for a conservative estimate of the relative number of thalamocortical and corticocortical excitatory synapses. However, networks that included substantially higher (yet anatomically plausible) percentages of cortical excitatory synapses sometimes exhibited less desirable properties. Although sharp orientation tuning could be achieved, trial-to-trial response variability was often high. For some parameters runaway cxcitation, similar to effects in models of epilcpsy (c.g., Traub and Miles, 1991), was observed. These problems were eliminated by reducing the number of excitatory synapses. Cortex appears to employ several different strategies for attenuating overly strong positive feedback. Cortical excitatory but not inhibitory cells rapidly adapt their firing rates (Connors et al., 1982; McCormick et al., 1985). Also EPSP amplitudes decline over the course of a single presynaptic spike train, perhaps due to presynaptic depression of transmitter release (Nelson and Smetters, 1993; Thomson and Deuchars, 1994) or to postsynaptic desensitization of glutamate receptors (Hestrin, 1992). These mechanisms presumably provide the cortex with important temporal gain control, but are beyond the present scope of the model. One temporal-based gain control mechanism was implemented in the model by providing faster thalamocortical excitation to cortical inhibitory cells than to cortical excitatory cells (Freund et al., 1985). This temporal offset was not required for sharp tuning; however, it substantially reduced the net levels of inhibition required. Modest feedforward inhibition can be as effective as stronger feedback inhibition in the control of recurrent excitation (Douglas and Martin, 1991). The model is not wedded to this particular temporal gain control mechanism; any of those listed above and possibly others may have equivalent effects.

\section{Experimental predictions}

The model has several experimental implications. It predicts that bicuculline application yields substantial broadening of EPSP tuning; feedforward and inhibitory models predict no change. The emergent model predicts that cells with moderately orientation-biased LGN inputs can exhibit unoriented responses with bicuculline. Inhibitory models predict only broadening to thalamic tuning levels. Thus, the emergent model may account more accurately for bicuculline effects than do inhibitory models, several of which were proposed on the basis of this data (e.g., Sillito et al., 1980). Additionally, the model suggests that strong IPSP levels may be observed in cells whose tuning has been abolished by bicuculline. Such a result, if found experimentally, would be inconsistent with inhibitory models. The model also predicts that under intracellular inhibitory blockade, a modest broadening of output response tuning will occur when no hypcrpolarizing current is applied. This broadening is subtle in the model and experimental detection would require sampling stimulus orientations at higher resolution than has been done (Nelson et al., 1994). Pure inhibitory models would predict either substantial broadening (to the levels exhibited under bicuculline) or substantial response attenuation (since sharp tuning in these models would require that the hyperpolarizing current be quite strong); neither effect is consistent with experiment.

An ideal experiment to test the model would seem to be to silence intracortical excitation and look for a broadening of orientation selectivity. Should this experiment prove feasible, it will be critical to properly control for response amplitude to avoid "iceberg" effects. Specifically, the model predicts that silencing of intracortical excitation will produce greater attenuation of preferred responses than nonpreferred responses. Sharp orientation tuning emerged quite rapidly within simulated response traces (cf. Vogels and Orban, 1991); however, the model does predict some, fast temporal evolution of tuning. A recent intracellular study showing sharpening of orientation selectivity in the first tens of milliseconds of responses confirms this prediction (Pei et al., 1994; Volgushev et al., 1995).

\section{Other models and phenomena}

Cross-orientation inhibition has frequently been proposed as a key mechanism in the generation of cortical orientation selectivity (Bishop et al., 1973; Sillito, 1979; Morrone et al., 1982; Matsubara et al., 1987; Eysel et al., 1990; Crook and Eysel, 1992). In contrast, the model presented here specifically excluded direct inputs from neurons preferring cross-orientations, to demonstrate that these connections are not necessary. Inclusion of cross-orientation inhibitory inputs into our model would have little effect on orientation selectivity; the inhibition would only further suppress the already weak responses to orthogonal stimuli. In the model, IPSPs were strongest at the preferred orientation. At greater orientation differences cortical IPSPs became progressively weaker, but the withdrawal of thalamocortical excitation from opposite polarity subfields grew stronger. Consistent with intracellular recordings (Ferster, 1986; Douglas et al., 1991a; Ferster and Jagadeesh, 1992; see Pei et al., 1994, for a differing view), the model required little cross-orientation inhibition, because little cross-orientation excitation was evoked. This view appears to differ from recent extracellular recordings that suggest "flat" or orientation nonspecific inhibition, possibly 
combined with inhibitory peaks just beyond the excitatory range (Hess and Murata, 1974; Ramoa et al., 1986; Bonds, 1989; DeAngelis et al., 1992). We suggest that these views can be reconciled by considering excitatory masking effects. At preferred orientations, strong excitation obscures detection of inhibition, while at orthogonal orientations withdrawal of excitation may be mistaken for inhibition. Although our model does not argue directly against the existence of cross-orientation inhibition, it suggests such inhibition is not necessary for orientation selectivity and may be of little utility.

The degree and forms of linearity exhibited by visual cortical neurons has been debated by many authors (e.g., Poggio and Reichardt, 1976; Movshon et al., 1978; Reid et al., 1987; Tolhurst and Dean, 1987, 1990; Albrecht and Geisler, 1991; Swindale, 1993; Ferster, 1994). Although these issues were not directly addressed in our simulations, several points are worth noting. In the emergent model synaptic potentials add and subtract linearly. This may prove consistent with a recent report that linear PSP summation underlies direction selectivity (Jagadeesh et al., 1993; see Suarez et al., 1995, for a related nonlinear model). The model also contains at least three sources of nonlinearity: action potential thresholds, voltage-dependent driving forces on synaptic potentials, and cortical amplification of responses. The emergent model is distinctly nonlinear, yet achieved functional properties (i.e., contrast-invariant orientation selectivity) similar to a recent "linear" model. The "normalization" model of Heeger (1992; Carandini and Heeger, 1994) employs strongly oriented LGN inputs with no cortical excitation. However, it also contains three forms of nonlinearity: rectifying thresholds; normalizing, divisive (or shunting) inhibition; and squaring of output responses (for other normalization models, see Grossberg, 1973; Albrecht and Geisler, 1991). Although the normalization model can account for a broad range of extracellular recording results, it is inconsistent with intracellular reports that crossorientation stimuli evoke only modest conductance changes and little net inhibition. The emergent model avoids shunting inhibition and the implausible response squaring function by implementing a nonlinear cortical gain control mechanism. Further research will be required to determine if this nonlinear mechanism can account for other forms of apparent linearity.

The emergent model demonstrates an orientation selectivity mechanism that relies on local, intracortical excitatory connections. The model's modest anatomical requirements could be satisfied independently in multiple cortical layers and areas (LeVay and Gilbert, 1976); thus, this mechanism may support the generation of orientation selectivity at parallel sites (Malpeli, 1983; Malpeli et al., 1986). Correlation studies, which suggest that complex cells receive intracortical excitatory input from other complex cells but not from simple cells (Toyama et al., 1981; Ghose et al., 1994), argue against a hierarchical orientation mechanism for complex cells. Since the emergent model does not require simple cell subfield interactions, it may be applicable to complex cells.

Local recurrent excitatory connections have previously been suggested to play an important role in cortical circuitry (e.g., Douglas and Martin, 1991; Douglas et al., 1991b). The utility of recurrent, center-surround architectures has also been noted in the neural networks literature (Wilson and Cowan, 1972; Grossberg, 1973; Kohonen, 1984). Here, a clear and compelling case has been made for the computational utility of local intracortical excitation in the generation of a well-defined cortical response property. In theory, orientation selectivity could be generated by any of several "simpler" mechanisms. The demonstration here that a recurrent excitatory mechanism provides the best account of a broad range of experimental data leads one to speculate that positive feedback may be a central feature of the computational style of the neocortex. Positive feedback amplification, in an architecture that features mildly biased afferent inputs and adaptive inhibitory levels, appears well suited to yield robust signal extraction, responsiveness to multiple stimulus dimensions, and context-dependent dynamic responses-all of which are typical of cortical neurons.

\section{References}

Ahmed BA, Anderson JC, Douglas RJ, Martin KAC, Nelson JC (1994) Polyneuronal innervation of spiny stellate neurons in cat visual cortex. J Comp Neurol 341:39-49.

Albrecht DG, Geisler W (1991) Motion selectivity and the contrastresponse function of simple cells in the striate cortex. Vis Neurosci 7:531-546.

Anderson JC, Douglas RJ, Martin KAC, Nelson JC (1994a) Synaptic output of physiologically identified spiny stellate neurons in cat visual cortex. J Comp Neurol 341:16-24.

Anderson JC, Douglas RJ, Martin KAC, Nelson JC (1994b) Map of the synapses formed with the dendrites of spiny stellate neurons of cat visual cortex. J Comp Neurol 341:25-38.

Beaulieu C, Colonnier M (1983) The number of neurons in the different laminae of the binocular and monocular regions of area 17 in the cat. J Comp Neurol 217:337-344.

Beaulieu C, Colonnier M (1985) A laminar analysis of the number of round asymmetrical and flat symmetrical synapses on spines, dendritic trunks, and cell bodics in area 17 of the cat. J Comp Neurol 231:180-189.

Beaulieu C, Somogyi P (1990) Targets and quantitative distribution of GABAergic synapses in the visual cortex of the cat. Eur J Neurosci 2:296-303.

Bell AJ, Mainen ZF, Tsodyks M, Sejnowski TJ (1995) "Balancing" of conductances may explain irregular cortical spiking. Technical report 1NC-9502. San Diego: Institute for Neural Computation, UCSD.

Berman NJ, Douglas RJ, Martin KAC, Whitteridge D (1991) Mechanisms of inhibition in cat visual cortex. J Physiol (Lond) 440:697722.

Bishop PO, Coombs JS, Henry GH (1973) Receptive fields of simple cells in the cat striate cortex. J Physiol (Lond) 231:31-60.

Bonds AB (1989) Role of inhibition in the specification of orientation sclectivity of cells in the cat striate cortcx. Vis Neurosci 2:41-55.

Bonds AB (1993) The encoding of cortical contrast gain control. In: Contrast sensitivity (Shapley RM, Lam D-K, eds), pp 215-230. Cambridge, MA: MIT Press.

Bush PC, Sejnowski TC (1994) Effects of inhibition and dendritic saturation in simulated neocortical pyramidal cells. J Neurophysiol 74: 2183-2193.

Carandini M, Heeger DJ (1994) Summation and division by neurons in primate visual cortex. Science 264:1333-1336.

Chapman B, Zahs KR, Stryker MP (1991) Relation of cortical cell orientation selectivity to alignment of receptive fields of the geniculocortical afferents that arborize within a single orientation column in ferret visual cortex. $\mathrm{J}$ Neurosci 11:1347-1358.

Chino YM, Kaplan E (1988) Abnormal orientation bias of LGN neurons in strabismic cats. Invest Ophthalmol Vis Sci 29:644-648.

Connors BW, Gutnick MJ, Prince DA (1982) Electrophysiological properties of neocortical neurons in vitro. J Neurophysiol 48:13021320.

Creutzfeldt OD, Kuhnt U, Benevento LA (1974a) An intracellular analysis of visual cortical neurons to moving stimuli: responses in a cooperative neuronal network. Exp Brain Res 21:251-274.

Creutzfeldt OD, Innocenti G, Brooks D (1974b) Vertical organization in the visual cortex (area 17). Exp Brain Res 21:315-336.

Crook JM, Eysel UT (1992) GABA-induced inactivation of functionally characterized sites in cat visual cortex (area 18): effects on orientation tuning. J Neurosci 12:1816-1825.

Dean AF, Tolhurst DJ (1986) Factors influencing the temporal phase of response to bar and grating stimuli for simple cells in the cat striate cortex. Exp Brain Res 62:143-151.

DeAngelis GC, Robson JG, Ohzawa I, Freeman RD (1992) Organi- 
zation of suppression in receptive fields of neurons in cat visual cortex. J Neurophysiol 68:144-163.

Dehay C, Douglas RJ, Martin KAC, Nelson C (1991) Excitation by geniculocortical synapses is not "vetoed" at the level of dendritic spines in cat visual cortex. J Physiol (Lond) 440:723-734.

Douglas RJ, Martin KAC (1991) A functional microcircuit for cat visual cortex. J Physiol (Lond) 440:735-769.

Douglas RJ, Martin KAC, Whitteridge D (1988) Selective responses of visual cortical neurones do not depend on shunting inhibition. Nature 332:642-644.

Douglas RJ, Martin KAC, Whitteridge D (1991a) An intracellular analysis of the visual responses of neurones in cat visual cortex. J Physiol (Lond) 44:659-696.

Douglas RJ, Martin KAC, Whitteridge D (1991b) A canonical microcircuit for neocortex. Neural Comput 1:480-488.

Einstein G, Davis TL, Sterling P (1987) Pattern of lateral geniculate synapses on neuron somata in layer IV of the cat striate cortex. $J$ Comp Neurol 260:76-86.

Enroth-Cugell C, Robson JG, Schweizer-Tong DE, Watson AB (1983) Spatio-temporal interactions in cat retinal ganglion cells showing linear spatial summation. J Physiol (Lond) 341:279-307.

Eysel UT, Crook JM, Machemer HF (1990) GABA-induced remote inactivation reveals cross-orientation inhibition in the cat striate cortex. Exp Brain Res 80:626-630.

Ferster D (1986) Orientation selectivity of synaptic potentials in neurons of cat primary visual cortex. J Neurosci 6:1284-1301

Ferster D (1987) Origin of orientation-selective LPSPs in simple cells of the cat visual cortex. J Neurosci 7:1780-1791.

Ferster D (1994) Linearity of synaptic interactions in the assembly of receptive fields in cat visual cortex. Curr Opin Neurobiol 4:563-568.

Ferster D, Jagadeesh B (1992) EPSP-IPSP interactions in cat visual cortex studied with in vivo whole-cell patch recording. J Neurosci 12:1262-1274.

Ferster D, Koch C (1987) Neuronal connections underlying orientation selectivity in cat visual cortex. Trends Neurnsci 10:487-492.

Freund TF, Martin KAC, Somogyi P, Whitteridge D (1985) Innervation of cat visual areas 17 and 18 by physiologically identified $\mathrm{X}$ - and Y-type thalamic afferents. II. Identification of postsynaptic targets by GABA immunocytochemistry and golgi impregnation. J Comp Neurol 242:275-291.

Gabbott PLA, Somogyi P (1986) Quantitative distribution of GABAimmunoreceptive neurons in the visual cortex (area 17) of the cat. Exp Brain Res 61:323-331.

Garey LJ, Powell TPS (1971) An experimental study of the termination of the lateral geniculo-cortical pathway in the cat and monkey. Proc R Soc Lond [Biol] 179:41-63.

Ghose GM, Freeman RD, Ohzawa I (1994) Local intracortical connections in the cat's visual cortex: postnatal development and plasticity. J Neurophysiol 72:1290-1303.

Gilbert CD, Wiesel TN (1983) Clustered intrinsic connections in cat visual cortex. J Neurosci 3:1116-1133.

Grossberg S (1973) Contour enhancement, short-term memory, and constancies in reverberating neural networks. Stud Appl Math 52: 217-257.

Grossberg S (1983) The quantized geometry of visual space: the coherent computation of depth, form, and lightness. Behav Brain Sci 6:625-692.

Grossberg S, Mingolla E (1987) Neural dynamics of surface perception: boundary webs, illuminants, and shape-from-shading. Comput Vis Graph Image Process 37:116-165.

Grossberg S, Olson SJ (1994) Rules for the cortical map of ocular dominance and orientation columns. Neural Networks 7:883-894.

Hata Y, Tsumoto T, Sato H, Hagihara K, Tamura H (1988) Inhibition contributes to orientation selectivity in visual cortex of cat. Nature 335:815-817.

Heeger DJ (1992) Normalization of cell responses in cat striate cortex. Vis Neurosci 9:181-197.

Heggelund P (1981) Receptive field organization of simple cells in cat striate cortex. Exp Brain Res 42:89-98.

Heggelund P (1986) Quantitative studies of the discharge fields of single cells in cat striate cortex. J Physiol (Lond) 373:277-292

Hess R, Murata K (1974) Effects of glutamate and GABA on specific response properties of neurons in the visual cortex. Exp Brain Res $21: 285-297$

Hestrin S (1992) Activation and desensitization of glutamate-activated channels mediating fast excitatory synaptic currents in the visual cortex. Neuron 9:991-999.

Hornung JP, Garey LJ (1981) The thalamic projection to the cat visual cortex: ultrastructure of neurons identified by Golgi impregnation or retrograde horseradish peroxidase transport. Neuroscience 6:10531068.

Horton JC, Sherk H (1984) Receptive field properties in the cat's lateral geniculate nucleus in the absence of on-center retinal input. $J$ Neurosci 4:374-380.

Hubel DH, Wiesel TN (1962) Receptive fields, binocular interaction and functional architecture in the cat's visual cortex. J Physiol (Lond) 165:559-568.

Jagadeesh B, Wheat HS, Ferster D (1993) Linearity of summation of synaptic potentials underlying direction selectivity of simple cells of the cat visual cortex. Science 262:1901-1904

Jones JP, Palmer LA (1987) The two-dimensional spatial structure of simple receptive fields in cat striate cortex. J Neurophysiol 58:11871211.

Kaplan E, Purpura K, Shapley RM (1987) Contrast affects the transmission of visual information through the mammalian lateral geniculate nucleus. J Physiol (Lond) 391:267-288.

Kisvàrday ZF, Martin KAC, Whitteridge D, Somogyi P (1985) Synaptic connections of intracellularly filled clutch neurons, a type of small basket neuron in the visual cortex of the cat. $J$ Comp Neurol 241:111-137.

Kisvàrday ZF, Beaulieu C, Eysel UT (1993) Network of GABAergic large basket cells in cat visual cortex (area 18): implication for lateral disinhibition. J Comp Neurol 327:398-415.

Koch C, Poggio T (1985) The synaptic veto mechanism: does it underlie direction and orientation selectivity in the visual cortex? In: Models of the visual cortex (Rose DR, Dobson VG, eds), pp 408419. New York: Wiley.

Koch C, Douglas RJ, Wehmeier U (1990) Visibility of synaptically induced conductance changes: theory and simulations of anatomically characterized cortical pyramidal cells. J Neurosci 10:1728-1744.

Kohonen T (1984) Self-organization and associative memory. New York: Springer.

Komatsu Y, Nakajima S, Toyama K, Fctz E (1988) Intracortical connectivity revealed by spike-triggered averaging in slice preparations of cat visual cortex. Brain Res 442:359-362.

LeVay S (1986) Synaptic organization of claustral and geniculate afferents to the visual cortex of the cat. J Neurosci 6:3564-3575.

LeVay S, Gilbert CD (1976) Laminar patterns of geniculocortical projection in the cat. Brain Res 113:1-19.

Linsenmeier RA, Frishman LJ, Jakiela HG, Enroth-Cugell C (1982) Receptive field properties of $\mathrm{X}$ and $\mathrm{Y}$ cells in the cat retina deriven from contrast sensitivity measurements. Vision Res 22:1173-1183.

Malpeli JG (1983) Activity of cells in area 17 of the cat in absence of input from layer $\Lambda$ of lateral geniculate nucleus. J Neurophysiol 49 : 595-610.

Malpeli JG, Lee C, Schwark HD, Weyand TG (1986) Cat area 17. I. Pattern of thalamic control of cortical layers. J Neurophysiol 56: $1062-1073$.

Marr D, Hildreth E (1980) Theory of edge detection. Proc R Soc Lond [Biol] 207:187-217.

Martin KAC (1988) From single cells to simple circuits in the cerebral cortex. Q J Exp Physiol 73:637-702.

Mason A, Nicoll A, Stratford K (1991) Synaptic transmission between individual pyramidal neurons of the rat visual cortex in vitro. J Neurosci 11:72-84.

Matsubara JA, Cynader MS, Swindale NV (1987) Anatomical projections and physiological correlates of the intrinsic connections in cat area 18. I Neurosci 7:1428-1446.

McCormick DA, Connors BW, Lighthall JW, Prince DA (1985) Comparative electrophysiology of physiology of pyramidal and sparsely spiny stellate neurons of the neocortex. J Neurophysiol 54:782-806.

Michalski A, Gerstein GI, Czarkowska J, Tarnecki R (1983) Interactions between cat striate cortex neurons. Exp Brain Res 51:97-107

Miller KD (1992) Development of orientation columns via competition between on- and off-center inputs. Neuroreport 3:73-76.

Miller KD (1994) A model for the development of simple cell receptive fields and the ordered arrangement of orientation columns through activity-dependent competition between on- and off-center inputs. J Neurosci 14:409-441.

Morrone MC, Burr DC, Maffei L (1982) Functional implications of 
cross-orientation inhibition of visual cortical cells. I. Neurophysiological evidence. Proc R Soc Lond [Biol] 216:335-354.

Movshon JA, Thompson ID, Tolhurst DJ (1978) Spatial summation in the receptive fields of simple cells in the cat's striate cortex. J Physiol (Lond) 283:53-77.

Nelson SB (1991) Temporal interactions in the cat visual system. III. Pharmacological studies of cortical suppression suggest a presynaptic mechanism. J Neurosci 11:369-380.

Nelson SB, Smetters DK (1993) Short-term plasticity of minimal synaptic currents in visual cortical neurons. Soc Neurosci Abstr 19:263.7.

Nelson SB, Toth LJ, Sheth B, Sur M (1994) Orientation selectivity of cortical neurons persists during intracellular blockade of inhibition. Science 265:774-777.

Orban GA (1984) Neuronal operations in the visual cortex. Berlin: Springer.

Palmer LA, Davis TL (1981) Receptive field structure in cat striate cortex. J Neurophysiol 46:260-276.

Pei X, Vidyasagar TR, Volgushev M, Creutzfeldt OD (1994) Receptive field andalysis and orientation selectivity of postsynaptic potentials of simple cells in cat visual cortex. J Neurosci 14:7130-7140.

Peichl L, Wässle H (1979) Size, scatter and coverage of ganglion cell receptive field centers in the cat retina. J Physiol (Lond) 291:117141.

Peters A, Payne BR (1993) Numerical relationships between geniculocortical afferents and pyramidal cell modules in cat primary visual cortex. Cereb Cortex 3:69-78.

Peters A, Yilmaz E (1993) Neuronal organization in area 17 of cat visual cortex. Cereb Cortex 3:49-68.

Poggio T, Reichardt WE (1976) Visual control of orienting behavior in the fly. II. Towards the underlying neural interactions. Q Rev Biophys 9:377-438.

Press WH, Flannery BP, Teukolsky SA, Vetterling WT (1992) Numerical recipes in C: the art of scientific computing, $2 \mathrm{~d}$ ed, pp 566-597. Cambridge: Cambridge UP.

Ramoa AS, Shadlen M, Skottun BC, Freeman RD (1986) A comparison of inhibition in orientation and spatial frequency selectivity of cat visual cortex. Nature 321:237-239.

Reid, RC, Soodak RE, Shapley RM (1987) Linear mechanisms of direction selectivity in simple cells of cat striate cortex. Proc Natl Acad Sci USA 84:8740-8744.

Richter J, Ullman S (1982) A model for the temporal organization of $\mathrm{X}$ - and $\mathrm{Y}$ - type receptive fields in the primate retina. Biol Cybern 43:127-145.

Rodieck RW, Stone J (1965) Analysis of receptive fields of cat retinal ganglion cells. J Neurophysiol 28:833-849.

Rojer A, Schwartz EL (1990) Cat and monkey cortical columnar patterns modeled by band-pass-filtered $2 d$ white noise. Biol Cybern 62 : 381-391.

Schiller P (1982) Central connections of the retinal ON and OFF pathways. Nature 297:580-583.

Sclar G, Freeman RD (1982) Orientation selectivity in the cat's striate cortex is invariant with stimulus contrast. Exp Brain Res 46:457461 .

Shadlen M, Newsome W (1994) Noise, neural codes and cortical organization. Curr Opin Neurobiol 4:569-579.

Sherk H, Horton JC (1984) Receptive field properties in the cat's area 17 in the absence of on-center geniculate input. J Neurosci 4:381393.

Shou T, Leventhal AG (1989) Organized arrangement of orientationselective relay cells in the cat's dorsal lateral geniculate nucleus. J Neurosci 9:4287-4302.

Sillito AM (1975) The contribution of inhibitory mechanisms to the receptive field properties of neurones in the striate cortex of the cat. J Physiol (Lond) 250:305-329.

Sillito AM (1979) Inhibitory mechanisms influencing complex cell orientation selectivity and their modification at high resting discharge levels. J Physiol (Lond) 289:33-53.

Sillito AM, Kemp JA, Milson JA, Berardi N (1980) A re-evaluation of the mechanisms underlying simple cell orientation selectivity. Brain Res 194:517-520.

Smetters DK, Nelson SB (1993) Estimates of functional synaptic con- vergence in rat and cat visual cortical neurons. Soc Neurosci Abstr 19:263.6.

Softky WR, Koch C (1993) The highly irregular firing of cortical cells is inconsistent with temporal integration of random EPSPs. J Neurosci $13: 334-450$.

Somers DC, Nelson SB, Sur M (1993) Computational model of the effects of short-range excitation and inhibition on orientation selectivity in visual cortex. Soc Neurosci Abstr 19:263.5.

Somers DC, Nelson SB, Sur M (1994) Effects of long-range connections on gain control in an emergent model of visual cortical orientation selectivity. Soc Neurosci Abstr 20:646.7.

Somers DC, Nelson SB, Sur M (1995) An emergent model of visual cortical orientation selectivity. In: Computation and neural systems: 1994 proceedings (Bower JM, ed), in press. Norwell, MA: Kluwer.

Soodak RE, Shapley RM, Kaplan E (1987) Linear mechanism of orientation tuning in the retina and lateral geniculate nucleus of the cat. J Neurophysiol 58:267-275.

Suarez H, Koch C, Douglas R (1995) Direction selectivity in primary visual cortex using massive intracortical connections. In: Advances in neural information processing systems, Vol 6, in press. Kauffman.

Swindale NV (1992) A model for the coordinated development of columnar systems in primate striate cortex. Biol Cybern 66:217-230.

Swindale NV (1993) Contrast integration along the length axis of area 17 neurons: linear or non-linear? Soc Neurosci Abstr 19:263.1.

Szentàgothai $\mathbf{J}$ (1965) The use of degeneration in the investigation of short neuronal connections. In: Progress in brain research (Singer M, Shade .IR, eds), pp 1-32. Amsterdam: Elsevier.

Thomson AM, Deuchars J (1994) Temporal and spatial properties of local circuits in neocortex. Trends Neurosci 17:119-126.

Tolhurst DJ, Dean AF (1987) Spatial summation by simple cells in the striate cortex of the cat. Exp Brain Res 66:607-620.

Tolhurst DJ, Dean AF (1990) The effects of contrast on the linearity of spatial summation of simple cells in the cat's striate cortex. Exp Brain Res 79:582-588.

Toyama K, Kimura M, Tanaka K (1981) Organization of cat visual cortex as investigated by cross-correlation technique. J Neurophysiol 46:202-214.

Traub RD, Miles R (1991) Neuronal networks of the hippocampus. Cambridge: Cambridge UP.

Tsodyks M, Bell A, Mainen ZF, Sejnowski TJ (1994) Why do cortical neurons fire irregularly? Soc Neurosci Abstr 20:627.8

Tsumoto T, Eckart W, Creutzfeldt OD (1979) Modification of orientation sensitivity of cat visual cortex neurons by removal of GABAmediated inhibition. Exp Brain Res 34:351-363.

Usher M, Stemmler M, Koch C, Olami Z (1994) Network amplification of local fluctuations causes high spike variability, fractal firing patterns, and oscillatory field potentials. Neural Comput 6:795-836.

Vidyasagar TR, Urbas JV (1982) Orientation sensitivity of cat LGN neurones with and without inputs from visual cortical areas 17, 18 . Exp Brain Res 46:157-169.

Vogels R, Orban GA (1991) Quantitative study of striate single unit responses in monkeys performing an orientation discrimination task. Exp Brain Res 84:1-11.

Volgushev M, Vidyasagar TR, Pei X (1995) Dynamics of the orientation tuning of post-synaptic potentials in the cat visual cortex. Vis Neurosci, in press.

Watkins DW, Berkley MA (1974) The orientation selectivity of single neurons in cat striate cortex. Exp Brain Res 19:433-446.

Wehmeier U, Dong D, Koch C, Van Essen D (1989) Modeling the visual system. In: Methods in neuronal modeling (Koch C, Segev I, eds), pp 335-359. Cambridge, MA: MIT Press.

White EL (1989) Cortical circuits. Boston: Birkhauser.

Wilson HR, Cowan JD (1972) Excitatory and inhibitory interactions in localized populations of model neurons. Biophys $\mathrm{J}$ 12:1-24.

Winfield DA, Powell TPS (1983) Laminar cell counts and geniculocortical boutons in area 17 of cat and monkey. Brain Res 227:223229.

Wörgotter F, Koch C (1991) A detailed model of the primary visual pathway in the cat: comparison of afferent excitatory and intracortical inhibitory connection schemes for orientation selectivity. J Neurosci 11:1959-1979. 